\title{
Factors Affecting Carbonation of Railway Rigid-Frame Viaducts
}

\author{
Chikara Kawamura ${ }^{1}$, Yukihiro Tanimura ${ }^{2}$, Masamichi Sogabe ${ }^{3}$, Koji Matsuhashi $^{4}$, Tsutomu Sato ${ }^{5}$ \\ and Tamon Ueda ${ }^{6}$
}

Received 31 October 2005, accepted 10 April 2006

\begin{abstract}
Recent years have seen a considerable amount of research on the carbonation of concrete. The standard specifications for concrete structures, outlined by the Japan Society of Civil Engineers (JSCE), prescribe a method to verify the durability of concrete structures in relation to carbonation. However, as the carbonation rate is largely governed by environmental conditions, it is important to quantitatively assess the effect of these conditions on the carbonation of concrete structures by applying the method to actual structures.

The factors affecting the progress of carbonation in different members were investigated based on the results of a survey on a rigid-frame railway viaduct in service since its construction several decades before. The study results indicate that the carbonation rate of columns varies with height and depends on the exposure condition to rainwater. In contrast, the dispersion of the carbonation depth on beams and slabs is small when compared to that of the carbonation depth on columns.
\end{abstract}

\section{Introduction}

Carbonation of the concrete material in reinforced concrete $(\mathrm{RC})$ structures causes steel reinforcement corrosion, and may lead to problems from a maintenance point of view. As concrete is carbonized due to the effects of the carbon dioxide in the atmosphere, carbonation will potentially be seen in many RC structures. This is an important issue in the discussion of the durability of RC structures.

The standard specifications for concrete structures (JSCE 2002) specify a method of verifying the durability concerning carbonation. The design value of carbonation depth is calculated as a function of several parameters, including the service period, the factors of environmental action, concrete material and the carbonation rate coefficient. Among the effects of these parameters, it is well

${ }^{1}$ Head, Construction Division, Engineering Department, Railway Operation Headquarters, Hokkaido Railway Company, Japan.

E-mail:c-kawamura@jrhokkaido.co.jp

2Senior Researcher, Concrete Structures, Structures Technology Division, Railway Technical Research Institute, Japan.

${ }^{3}$ Senior Researcher, Structural Mechanics, Railway Dynamics Division, Railway Technical Research Institute, Japan.

${ }^{4}$ Researcher, Concrete Structures, Structures Technology Division, Railway Technical Research Institute, Japan.

${ }^{5}$ Chief , JR Affairs, Research and Development Promotion Division, Railway Technical Research Institute, Japan.

${ }^{6}$ Professor, Division of Structural and Geotechnical Engineering, Hokkaido University, Japan. known that the carbonation depth is approximately proportional to the square root of the service period (Izumi et al. 1986). In addition, the carbonation rate coefficient, indicating the relationship between the carbonation depth and the square root of the service period, shows a high correlation with the water binder ratio in the same considered environment. An evaluation method is provided from previous research (JSCE 1988).

However, a survey using actual structures indicates that carbonation depths at different measuring points in the structures show a wide range of variation and greatly exceed the estimated value in some structures (Ishibashi and Kitago 1987). Surveys on railway RC girders (Yachida et al. 1987), highway bridges (Imai et al. 1993, Edamoto et al. 1998) and other structures (Ikeda et al. 1983) have also established that the carbonation depth differs greatly between structures or at different portions in a structure. This is presumably because of differences in environmental conditions and concrete quality arising from variations in construction conditions at different portions.

In terms of environmental conditions, accelerated and exposure tests in past research (John et al. 1990, Uomoto and Takada 1992, Shirakawa et al. 1996) have shown that temperature, humidity and carbon dioxide concentration affects the carbonation rate. The carbonation rate of concrete is also governed by levels of moisture (Saeki et al. 1989), and differs according to whether the structure is exposed to rainwater (Saeki et al. 1991). It has been pointed out, however, that the carbonation of concrete in accelerated carbonation tests potentially presents a different trend from the conditions found in natural exposure tests (Saeki et al. 1990). As it is difficult to clarify environmental influences through experiments, it is necessary to clarify the factors affecting carbonation through detailed investigation. 
Previous research (Tanimura et al. 2004) clarified to some extent the carbonation rates in different members or at different portions in actual structures. However, there has been only a limited number of such surveys in the past.

Therefore, a detailed and extensive survey on an actual structure, in service since its construction several decades before, was conducted. The targeted structure was a typical railway viaduct consisting of an $\mathrm{RC}$ rigid-frame viaduct structure composed of beams and slabs.

\section{Summary of survey}

\subsection{Object structure}

Figure 1 shows an outline of the object structure. The track runs from south to north. There are seven viaducts (R1 to R7) in the survey section, with four spans in the track direction of viaduct $\mathrm{R} 1$, and five each in viaducts R2 to R7. According to the design specifications of this structure, the characteristic compressive strength of concrete is: $f^{\prime}{ }_{\mathrm{ck}}=27\left(\mathrm{~N} / \mathrm{mm}^{2}\right)$ and the concrete cover of the reinforcing steel bars is $30 \mathrm{~mm}$. The surfaces of the viaducts are not finished or painted, and there are few cracks or other external abnormalities. The space under the viaducts is vacant, without structures or other such obstacles, and the ground surface is an uncovered concrete surface or concrete surface paved with asphalt.
Surrounding the viaducts are a vacant space extending $500 \mathrm{~m}$ eastward to the seashore and farms and woodland spreading westward. The normal temperature in the region where the structures are located in is approximately 17.3 degrees Celsius. The temperature fluctuation band in one year is approximately 20.0 degrees Celsius. Normal humidity is 74.0 percent. (Statistic from 1971 to 2000)

\subsection{Survey methods}

There are two methods for measuring the carbonation depth of concrete. One method (referred to below as the chipping method) involves chipping the concrete structure with an electric pick, spraying a $1 \%$ solution of phenolphthalein on the chipped surface and measuring the distance from the surface to the color development point. The other method (referred to below as the drilling method) involves drilling a hole $10 \mathrm{~mm}$ in diameter in the concrete, collecting the discharged concrete powder using filter paper moistened with a $1 \%$ solution of phenolphthalein, and measuring the hole depth with calipers when the concrete powder starts to change color (Kasai and Yuasa 1998). To clarify differences in carbonation depth in different members and at different portions, the simpler drilling method was adopted. This enabled the detailed distribution of carbonation depths assessment with a large number of measuring points. Past research

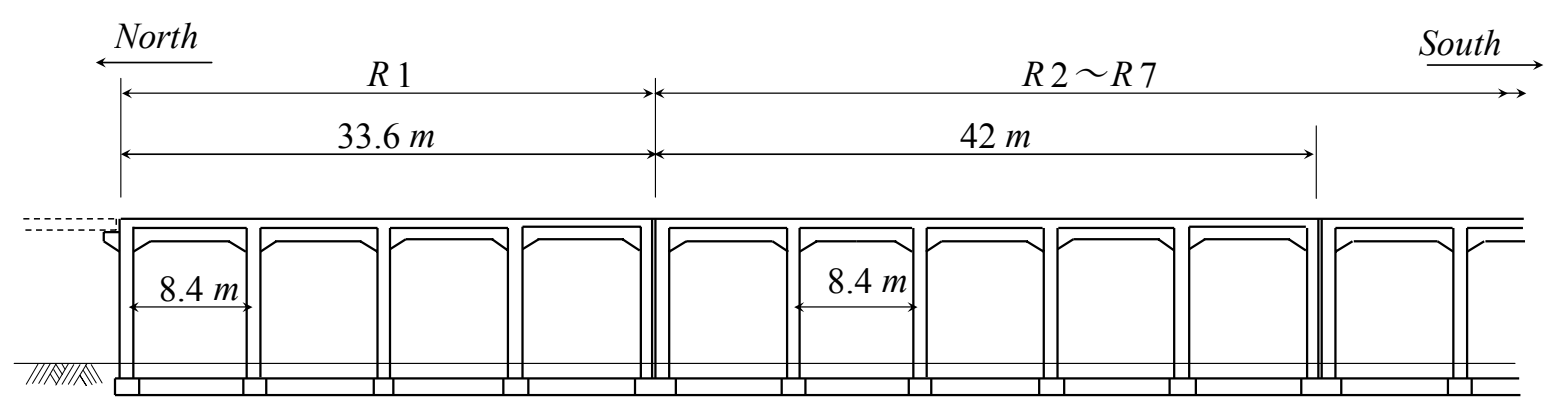

(a) Longitudinal section

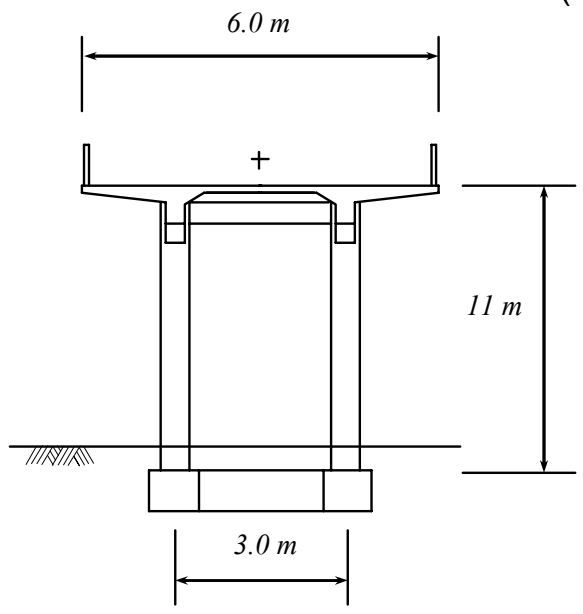

(b) Cross section

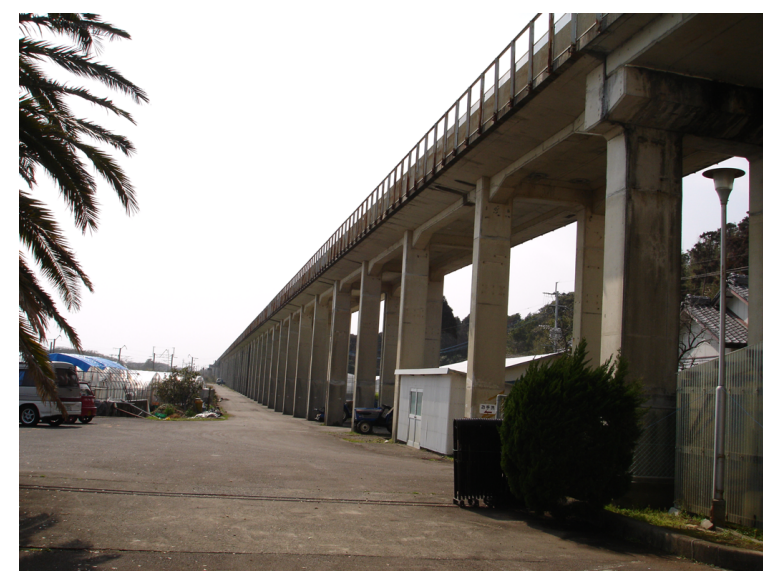

(c) Panoramic photograph from origin

Fig. 1 Outline of object structure. 
results (Tanimura et al. 2004, Nihei et al. 2004) demonstrated that measurements obtained using the drilling method are approximately in agreement with those obtained by the chipping method, with a difference of only up to $5 \mathrm{~mm}$ between these two methods.

Figures 2 to 6 show the measuring points on different members. Drilled holes are represented by black points.

\section{a) Measuring method for columns}

The numbers of carbonation depth measurements in columns are listed in Table 1, according to measuring patterns $\mathrm{A}, \mathrm{B}$ and $\mathrm{C}$ shown in Fig. 2. Figure 3 shows the definition of orientations and measurement surfaces of columns. Pattern A was applied to column surfaces in different orientations, and patterns $\mathrm{B}$ and $\mathrm{C}$ were applied to the inner surfaces of columns.

\section{b) Measuring method for beams}

The carbonation depth was measured on the sides of the beams according to measuring patterns D, E, F and G in Figs. 4 and 5. Table 2 lists the number of measuring points on each viaduct for each measuring pattern.

\section{c) Measuring method in slabs}

Carbonation depths were measured at the bottom of the overhanging and middle slabs according to measuring patterns $\mathrm{H}$ and $\mathrm{I}$ in Fig. 6. Table 3 lists the number of measuring points on each viaduct for each measuring pattern.

\section{Investigation on factors affecting carbonation rate}

\subsection{Measured carbonation depths}

Tables 4 to 6 list the number of carbonation depth measuring points (Points) in different members of each viaduct, the maximum value (Max), minimum value (Min), average value (Ave), standard deviation $(\sigma)$ and coefficient of variance $(\mathrm{Cv})$ of measurements. The average value is 5.0 to $11.2 \mathrm{~mm}$ for columns, 17.3 to 22.9 $\mathrm{mm}$ for beams and 14.3 to $21.4 \mathrm{~mm}$ for slabs. The ratio of the standard deviation to the average (i.e. coefficient of variance) is 0.33 to 0.57 for columns, 0.16 to 0.29 for beams and 0.17 to 0.41 for slabs.

\subsection{Carbonation depths at different points on columns}

a) Carbonation depth at different heights

Figure 7 show the distributions of carbonation depths in the vertical direction. Each carbonation depth at different heights in these figures is the average of the three measuring points at the corresponding height in Figs. 2(a) and (b). The dotted lines indicate the construction joints.

According to Fig. 7, the carbonation depth is larger in the section directly under the lower construction joint, which is $3 \mathrm{~m}$ from the ground, and smaller just above the construction joint. In the section between the higher and
Table1 Number of measured columns and surfaces.

\begin{tabular}{|c|c|c|c|c|c|c|c|c|c|c|c|}
\hline & \multicolumn{5}{|c|}{ Pattern A } & \multicolumn{2}{|c|}{ PatternB } & \multicolumn{2}{|c|}{ PatternC } & \multicolumn{2}{|c|}{ Total } \\
\hline & \multirow{2}{*}{$\mathrm{C}$} & \multicolumn{4}{|c|}{$\mathrm{S}$} & \multirow{2}{*}{$\mathrm{C}$} & \multirow{2}{*}{$\begin{array}{l}\mathrm{S} \\
\text { in }\end{array}$} & \multirow{2}{*}{$\mathrm{C}$} & \multirow{2}{*}{$\begin{array}{l}\mathrm{S} \\
\text { in }\end{array}$} & \multirow{2}{*}{$\mathrm{C}$} & \multirow{2}{*}{$\mathrm{S}$} \\
\hline & & in & out & No & So & & & & & & \\
\hline $\mathrm{R} 1$ & 0 & 0 & 0 & 0 & 0 & 0 & 0 & 10 & 10 & 10 & 10 \\
\hline $\mathrm{R} 2$ & 0 & 0 & 0 & 0 & 0 & 6 & 6 & 12 & 12 & 18 & 18 \\
\hline R3 & 0 & 0 & 0 & 0 & 0 & 4 & 4 & 12 & 12 & 16 & 16 \\
\hline $\mathrm{R} 4$ & 2 & 2 & 0 & 0 & 0 & 0 & 0 & 12 & 12 & 14 & 14 \\
\hline R5 & 0 & 0 & 0 & 0 & 0 & 0 & 0 & 12 & 12 & 12 & 12 \\
\hline R6 & 1 & 1 & 1 & 1 & 1 & 0 & 0 & 12 & 12 & 13 & 16 \\
\hline R7 & 1 & 1 & 1 & 1 & 1 & 0 & 0 & 12 & 12 & 13 & 16 \\
\hline tot & 4 & 4 & 2 & 2 & . & 10 & 10 & 82 & 82 & 96 & 10 \\
\hline
\end{tabular}

※C: Number of Columns, S: Surfaces of columns, In: Inner surface, Out: Outer surface, No: North surface, So: South surface

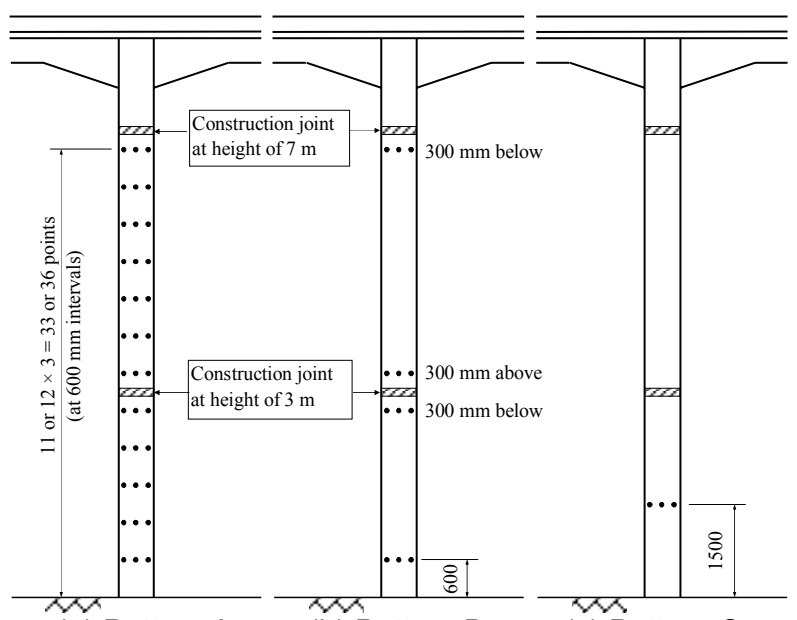
(a) Pattern A
(b) Pattern B
(c) Pattern C

Fig. 2 Measuring points in columns.

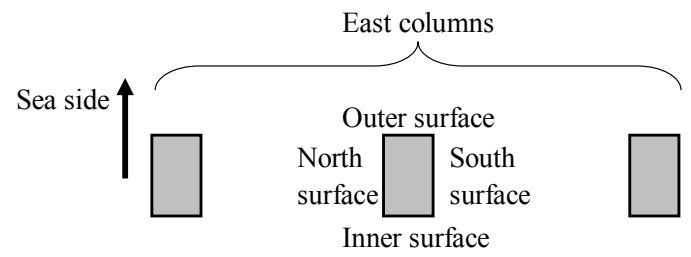

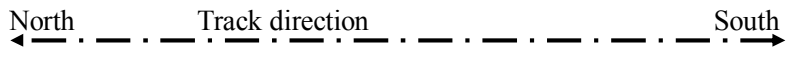

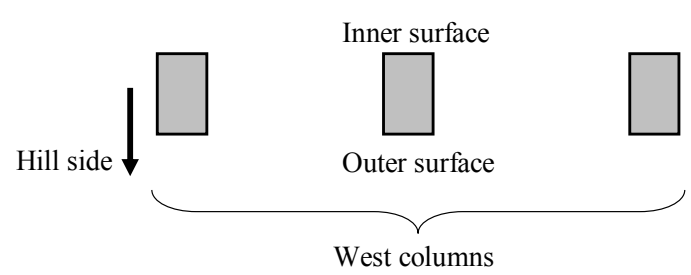

Fig. 3 Definition of orientations and measurement surfaces of columns.

the lower construction joints, or in the section of the second concrete casting, the carbonation depth tends to be smaller towards the bottom and larger towards the top. This phenomenon can be explained by considering that concrete quality just beneath a construction joint deteriorates due to bleeding in the section, and that the con- 


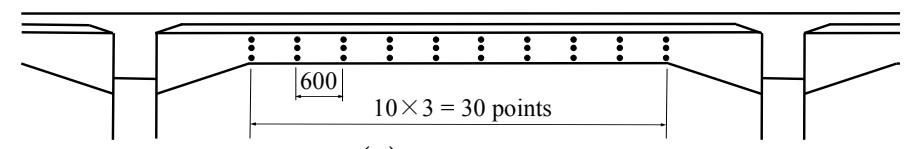

(a) Pattern D

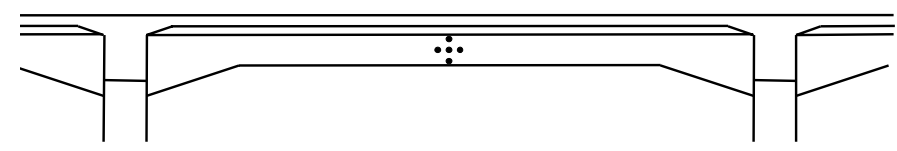

(b) Pattern E

Fig. 4 Measuring points in longitudinal beams.

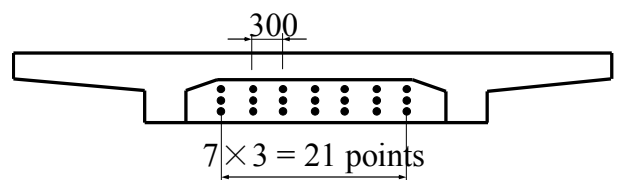

(a) Pattern F

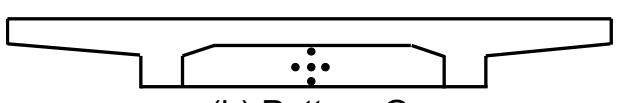

(b) Pattern G

Fig. 5 Measuring points in cross beams.

Table 2 Number of measured beams and surfaces.

\begin{tabular}{|c|c|c|c|c|c|c|c|c|c|c|}
\hline & \multicolumn{2}{|c|}{$\begin{array}{c}\text { Pattern } \\
\text { D }\end{array}$} & \multicolumn{2}{c|}{$\begin{array}{c}\text { Pattern } \\
\text { D }\end{array}$} & \multicolumn{2}{c|}{ Pattern } & \multicolumn{2}{c|}{ Pattern } & \multicolumn{2}{|c|}{ Total } \\
\cline { 2 - 13 } & L & S & L & S & C & S & C & S & Beams & S \\
\hline R1 & 0 & 0 & 1 & 1 & 0 & 0 & 0 & 0 & 1 & 1 \\
\hline R2 & 0 & 0 & 0 & 0 & 0 & 0 & 0 & 0 & 0 & 0 \\
\hline R3 & 0 & 0 & 0 & 0 & 0 & 0 & 0 & 0 & 0 & 0 \\
\hline R4 & 0 & 0 & 1 & 1 & 0 & 0 & 0 & 0 & 1 & 1 \\
\hline R5 & 0 & 0 & 0 & 0 & 0 & 0 & 0 & 0 & 0 & 0 \\
\hline R6 & 1 & 1 & 8 & 12 & 1 & 1 & 6 & 8 & 16 & 22 \\
\hline R7 & 1 & 1 & 8 & 12 & 1 & 1 & 6 & 8 & 16 & 22 \\
\hline Total & 2 & 2 & 18 & 26 & 2 & 2 & 12 & 16 & 34 & 46 \\
\hline
\end{tabular}

*L: Longitudinal beam, C: Cross beam, S: Surfaces of beams

Table 3 Number of measured slabs.

\begin{tabular}{|c|c|c|c|c|c|c|}
\hline \multirow{2}{*}{} & \multicolumn{2}{|c|}{ Pattern H } & \multicolumn{2}{c|}{ Pattern I } & \multicolumn{2}{c|}{ Total } \\
\cline { 2 - 7 } & $\mathrm{M}$ & $\mathrm{O}$ & $\mathrm{M}$ & $\mathrm{O}$ & $\mathrm{M}$ & $\mathrm{O}$ \\
\hline R1 & 1 & 1 & 1 & 1 & 2 & 2 \\
\hline R2 & 1 & 1 & 1 & 1 & 2 & 2 \\
\hline R3 & 1 & 1 & 1 & 1 & 2 & 2 \\
\hline R4 & 1 & 1 & 2 & 2 & 3 & 3 \\
\hline R5 & 1 & 1 & 4 & 4 & 5 & 5 \\
\hline R6 & 1 & 1 & 4 & 4 & 5 & 5 \\
\hline R7 & 1 & 1 & 4 & 4 & 5 & 5 \\
\hline Total & 7 & 7 & 17 & 17 & 24 & 24 \\
\hline
\end{tabular}

crete in the lower part is densely compacted by the self-weight of concrete when it is cast. From these findings, it can be inferred that the quality of concrete changes in the vertical direction, giving rise to different carbonation rates at different heights in concrete columns.

In Fig. 7, the carbonation depths of east columns are

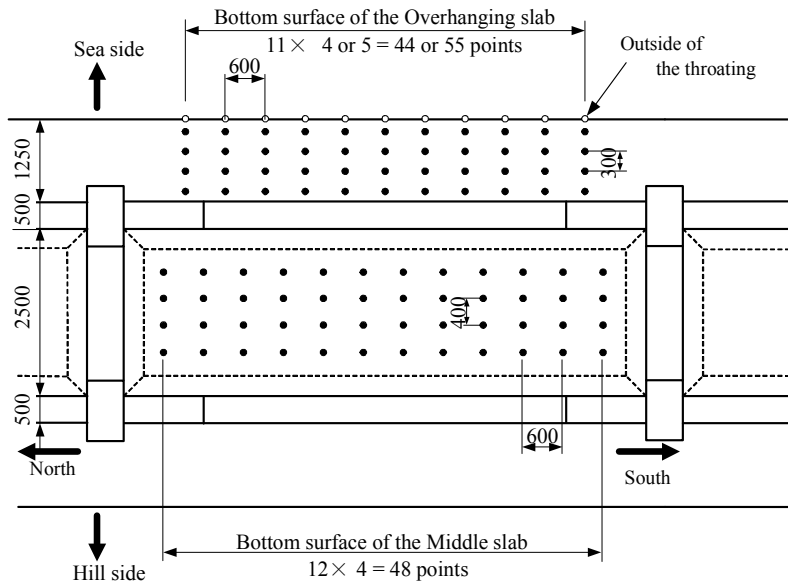

(a) Pattern H

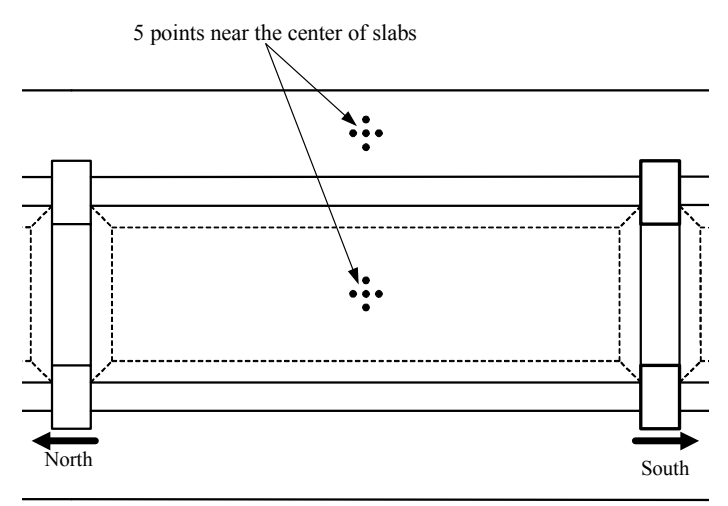

(b) Pattern I

Fig. 6 Measuring points in slabs.

comparatively larger than those of west columns. The inner surfaces of east columns are oriented toward the west and receive a little shade unlike the west columns because the mountain is near the west side of the structures. There is a possibility that this difference in the orientation of the surfaces of columns influences the carbonation depth.

Figure 8 shows the relationship between the carbonation depth of a column $600 \mathrm{~mm}$ from the ground and the carbonation depth just below the lower construction joint ( $3 \mathrm{~m}$ from the ground), measured according to pattern B. Since this measuring pattern is applied to the inner surfaces of columns, environmental conditions in this case do not fluctuate much along the vertical direction. 


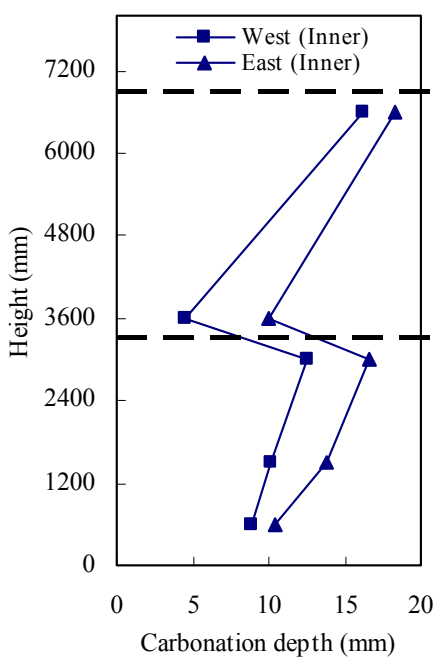

(a) R2 east and west column 1

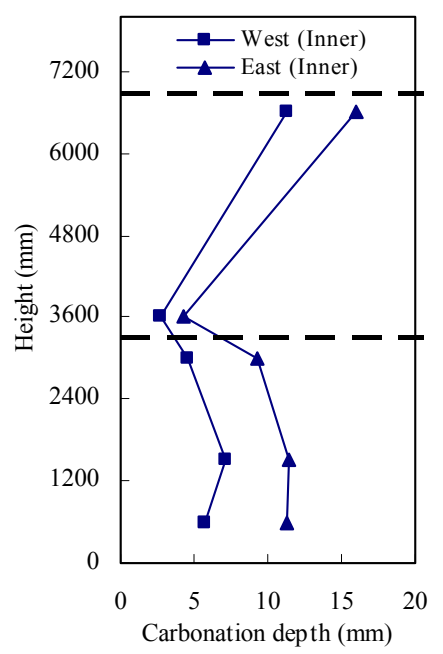

(d) R3 east and west column 1

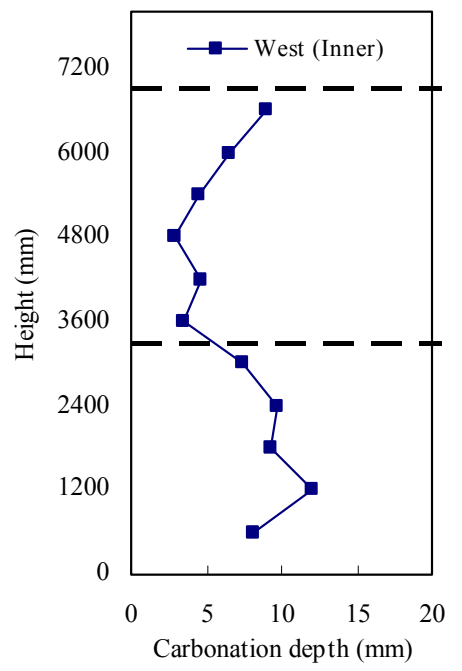

(g) R4 west column 2

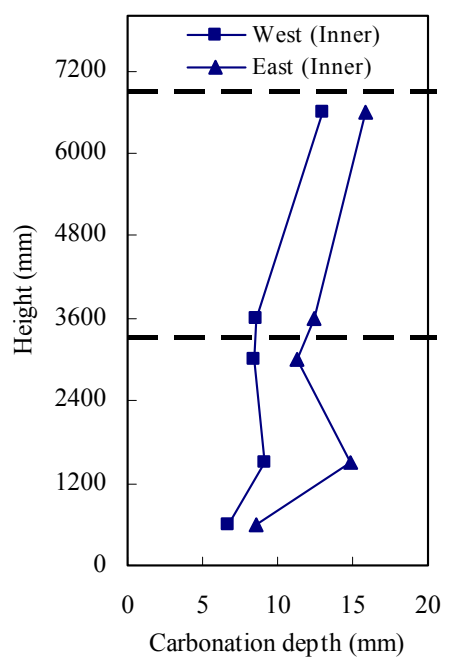

(b) R2 east and west column 2

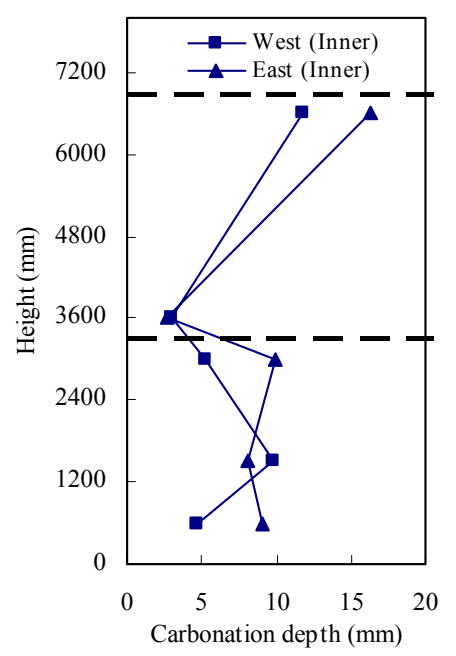

(e) R3 east and west column 2

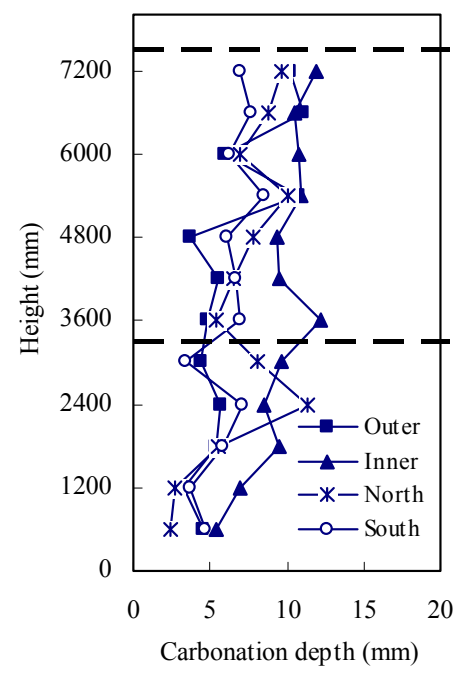

(h) R6 east column (4 surfaces)

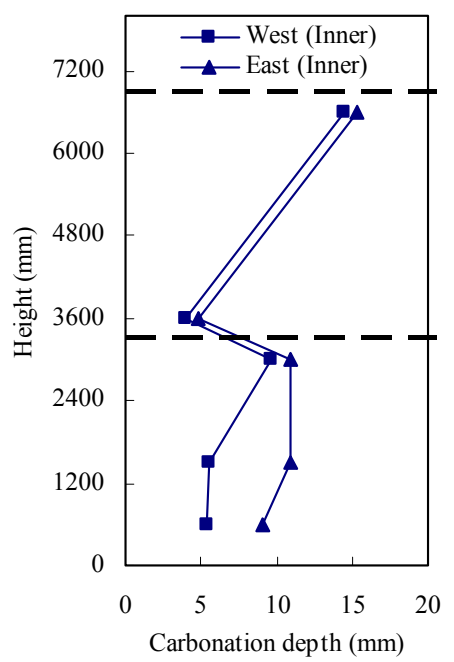

(c) R2 east and west column 3

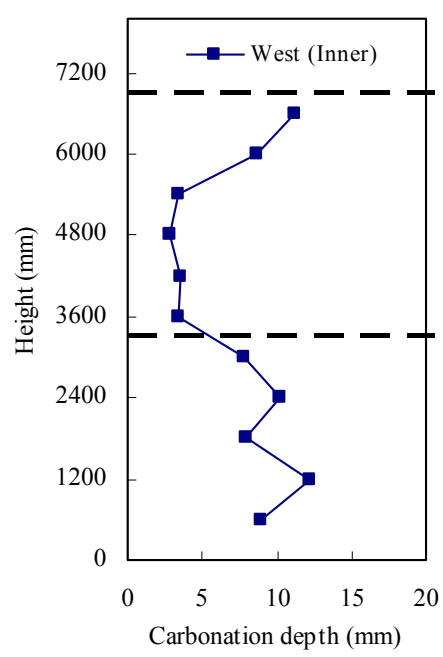

(f) R4 west column 1

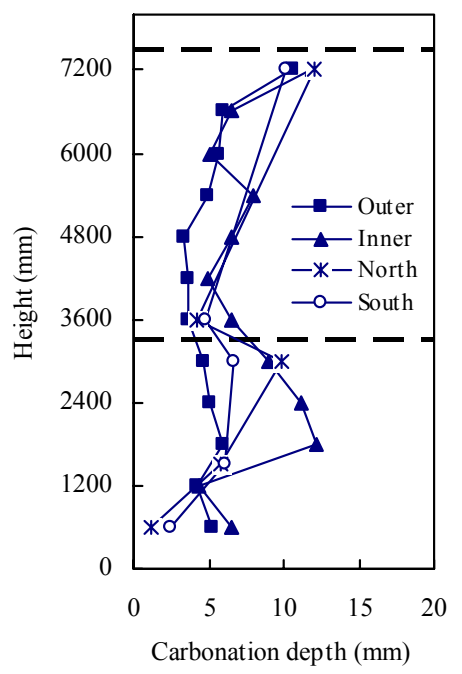

(i) R7 west column (4 surfaces ${ }^{*}$ )

*: North and South are measurements done in the past ${ }^{15)}$.

Fig. 7 Distributions of carbonation depth in the vertical direction of columns. 
Different carbonation depths at different points in the vertical direction are therefore predominantly governed by varying concrete qualities at different points along that direction. Figure 8 indicates that carbonation depths

Table 4 Measured carbonation depths in columns ( $\mathrm{mm})$.

\begin{tabular}{|c|c|c|c|c|c|c|}
\hline & Points & Max & Min & Ave & $\sigma$ & Cv \\
\hline R7 & 119 & 18.5 & 2.0 & 7.0 & 3.9 & 0.55 \\
\hline R6 & 204 & 26.6 & 1.2 & 8.3 & 4.5 & 0.54 \\
\hline R5 & 36 & 10.6 & 1.4 & 5.0 & 2.4 & 0.49 \\
\hline R4 & 114 & 17.7 & 2.1 & 8.0 & 3.9 & 0.49 \\
\hline R3 & 96 & 21.0 & 1.4 & 8.7 & 5.0 & 0.57 \\
\hline R2 & 126 & 30.0 & 2.3 & 11.2 & 5.2 & 0.47 \\
\hline R1 & 30 & 13.2 & 2.0 & 8.3 & 2.8 & 0.33 \\
\hline Total & 725 & 30.0 & 1.2 & 8.4 & 4.6 & 0.54 \\
\hline
\end{tabular}

Table 5 Measured carbonation depths in beams $(\mathrm{mm})$.

\begin{tabular}{|c|c|c|c|c|c|c|c|}
\hline & Beam & Points & Max & Min & Ave & $\sigma$ & $\mathrm{Cv}$ \\
\hline \multirow{2}{*}{ R1 } & $\mathrm{L}$ & 5 & 19.4 & 13.2 & 17.3 & 2.8 & 0.16 \\
\hline & $\mathrm{C}$ & 0 & --- & --- & +-- & --. & --- \\
\hline \multirow{2}{*}{$\mathrm{R} 2$} & $\mathrm{~L}$ & 0 & -- & $\cdots$ & $\cdots$ & $\cdots$ & $\cdots$ \\
\hline & $\mathrm{C}$ & 0 & $\cdots$ & $\cdots$ & --- & --- & -- \\
\hline \multirow{2}{*}{ R3 } & $\mathrm{L}$ & 0 & $\cdots$ & $\cdots$ & --- & $-\cdots$ & --- \\
\hline & $\mathrm{C}$ & 0 & --- & $\cdots$ & 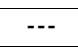 & $-\cdots$ & --- \\
\hline \multirow{2}{*}{$\mathrm{R} 4$} & $\mathrm{~L}$ & 5 & 28.0 & 16.1 & 22.9 & 4.4 & 0.19 \\
\hline & $\mathrm{C}$ & 0 & --- & --- & $-\cdot-$ & $-\cdots$ & $-\cdots$ \\
\hline \multirow{2}{*}{ R5 } & $\mathrm{L}$ & 0 & --- & -- & --- & $-\cdots$ & $--\cdot$ \\
\hline & $\mathrm{C}$ & 0 & $\cdots$ & $--\cdot$ & $\cdots$ & $-\cdots$ & $\cdots$ \\
\hline \multirow{2}{*}{ R6 } & $\mathrm{L}$ & 90 & 38.0 & 9.8 & 22.8 & 4.5 & 0.20 \\
\hline & $\mathrm{C}$ & 61 & 33.3 & 13.4 & 21.9 & 3.9 & 0.18 \\
\hline \multirow{2}{*}{ R7 } & $\mathrm{L}$ & 66 & 26.8 & 11.1 & 19.3 & 4.0 & 0.21 \\
\hline & $\mathrm{C}$ & 59 & 31.6 & 7.2 & 20.0 & 5.8 & 0.29 \\
\hline \multirow{2}{*}{ Total } & $\mathrm{L}$ & 166 & 38.0 & 11.1 & 21.0 & 4.4 & 0.21 \\
\hline & $\mathrm{C}$ & 120 & 31.6 & 8.0 & 21.0 & 4.6 & 0.22 \\
\hline
\end{tabular}

Table 6 Measurement results of slabs ( $\mathrm{mm})$.

\begin{tabular}{|c|c|c|c|c|c|c|c|}
\hline & Slab & Points & Max & Min & Ave & $\sigma$ & $\mathrm{Cv}$ \\
\hline \multirow{2}{*}{$\mathrm{R} 1$} & $\mathrm{M}$ & 53 & 26.2 & 7.4 & 15.0 & 3.9 & 0.26 \\
\hline & $\mathrm{O}$ & 49 & 39.8 & 4.7 & 16.5 & 5.4 & 0.33 \\
\hline \multirow{2}{*}{$\mathrm{R} 2$} & $\mathrm{M}$ & 53 & 21.7 & 4.0 & 15.8 & 3.9 & 0.25 \\
\hline & $\mathrm{O}$ & 49 & 22.0 & 7.2 & 16.1 & 2.8 & 0.17 \\
\hline \multirow{2}{*}{ R3 } & $\mathrm{M}$ & 53 & 24.0 & 8.3 & 16.2 & 4.0 & 0.25 \\
\hline & $\mathrm{O}$ & 49 & 26.5 & 8.4 & 16.1 & 4.5 & 0.28 \\
\hline \multirow{2}{*}{$\mathrm{R} 4$} & $\mathrm{M}$ & 58 & 25.0 & 11.3 & 17.2 & 3.2 & 0.19 \\
\hline & $\mathrm{O}$ & 54 & 28.0 & 6.7 & 16.7 & 3.6 & 0.22 \\
\hline \multirow{2}{*}{ R5 } & $\mathrm{M}$ & 68 & 38.8 & 2.8 & 18.0 & 7.4 & 0.41 \\
\hline & $\mathrm{O}$ & 64 & 33.4 & 8.7 & 21.4 & 5.1 & 0.24 \\
\hline \multirow{2}{*}{ R6 } & $\mathrm{M}$ & 68 & 32.4 & 2.8 & 14.3 & 5.6 & 0.39 \\
\hline & $\mathrm{O}$ & 68 & 32.6 & 6.0 & 17.3 & 4.5 & 0.26 \\
\hline \multirow{2}{*}{$\mathrm{R} 7$} & $\mathrm{M}$ & 64 & 26.8 & 8.0 & 16.1 & 3.2 & 0.20 \\
\hline & $\mathrm{O}$ & 60 & 25.0 & 8.6 & 17.0 & 3.2 & 0.19 \\
\hline \multirow{2}{*}{ Total } & $\mathrm{M}$ & 417 & 38.8 & 2.8 & 17.1 & 5.3 & 0.31 \\
\hline & $\mathrm{O}$ & 393 & 39.8 & 4.7 & 17.4 & 4.6 & 0.26 \\
\hline
\end{tabular}


tion depth values are comparatively small in Fig. 11. The

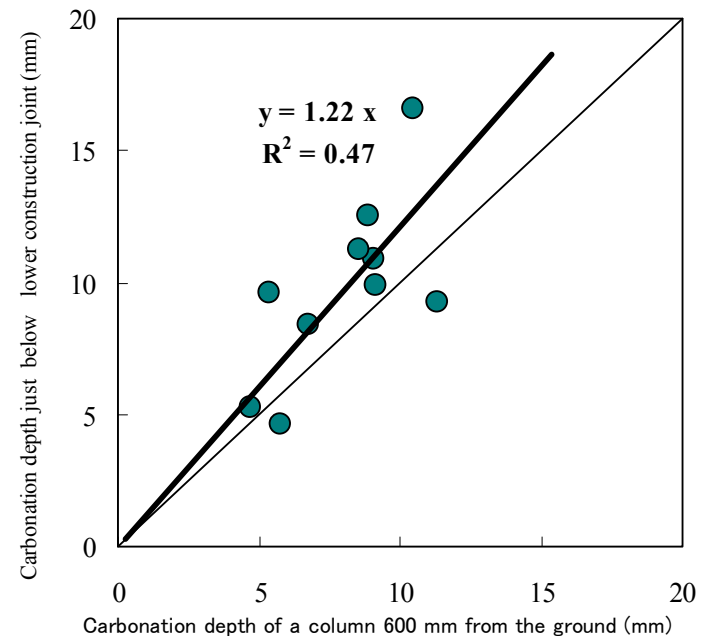

Fig. 8 Comparison of carbonation depth by lower part of columns.

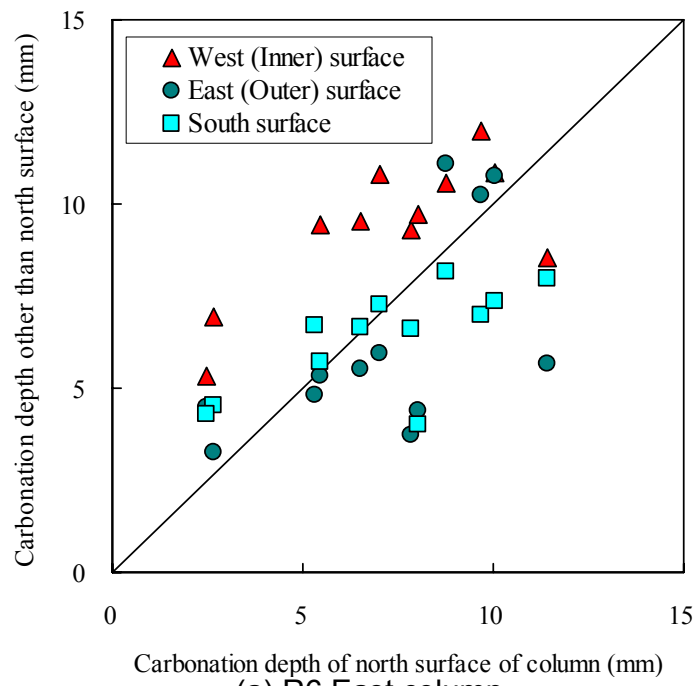

(a) R6 East column

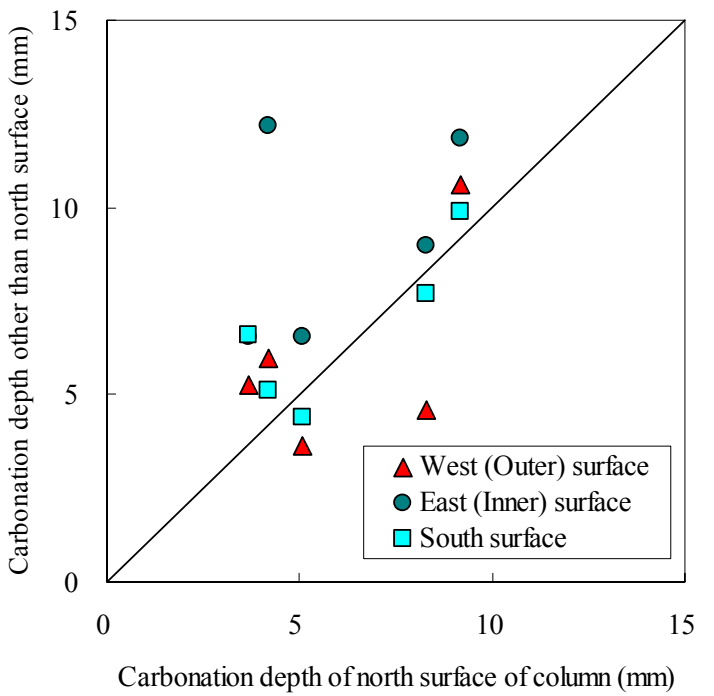

(b) R7 West column

Fig. 9 Comparison of carbonation depth by direction of column's surface. same tendency was seen in other surfaces of columns. Although there are indeterminate factors such as the influence of rainwater and wind direction on different days, the areas where the carbonation depth is small coincide, to a certain extent, with those exposed to rainwater.

c) Carbonation depth with different ground pavement conditions

To investigate the effect of ground pavement conditions on carbonation depth, Fig. 13 shows the distribution along the track direction of carbonation depths on the inner column surface at a point $1,500 \mathrm{~mm}$ from the ground (measured according to pattern $\mathrm{C}$ ) together with

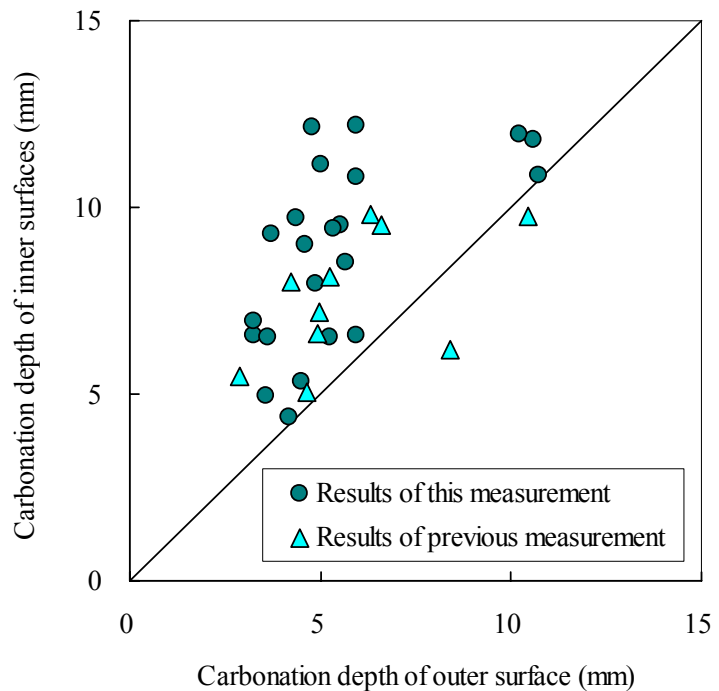

Fig.10 Comparison of inner surface's carbonation depth with outer surface.

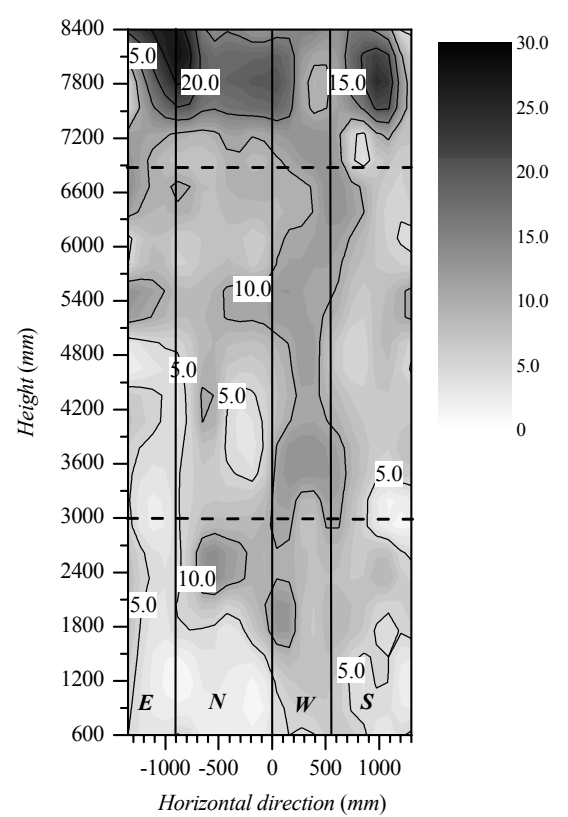

Fig. 11 Contour of carbonation depth of R6 East column. 


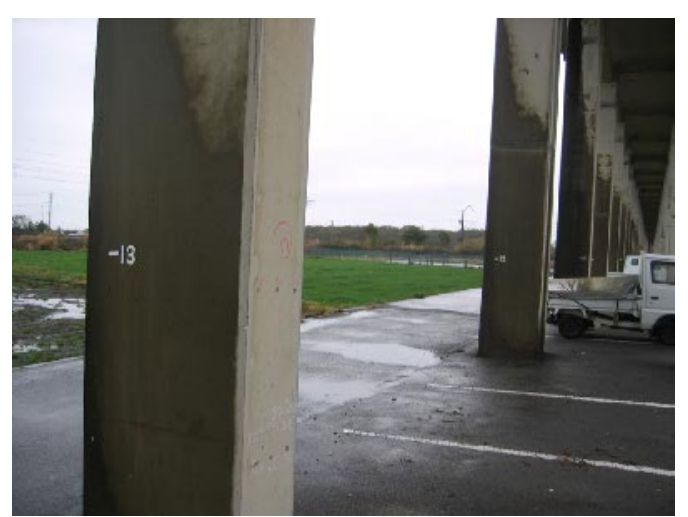

Fig. 12 Condition of columns exposed to rainwater (picture shot from north).

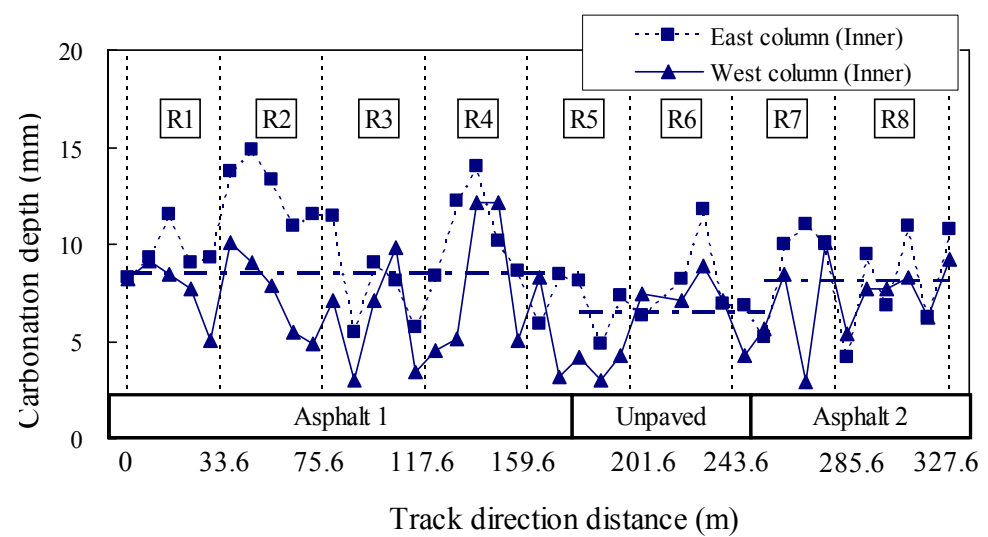

Fig. 13 Distribution of column's carbonation depth along track direction.

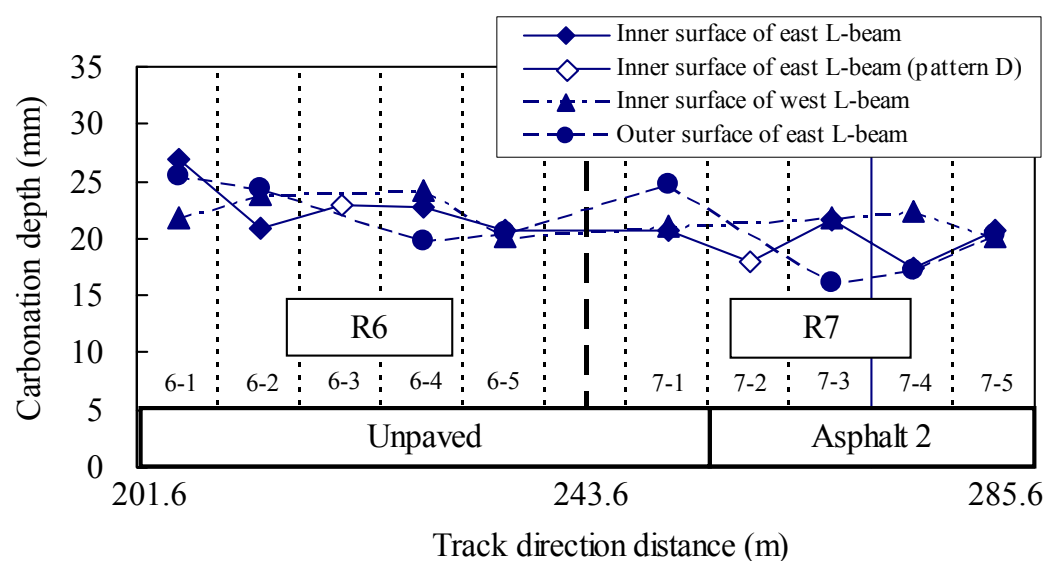

Fig. 14 Distribution in track direction of average carbonation depth on different longitudinal beam sides.

the ground pavement conditions at the measuring points. The average carbonation depth is $8.6 \mathrm{~mm}$ in the Asphalt 1 section, $6.5 \mathrm{~mm}$ in the Unpaved section and $8.1 \mathrm{~mm}$ in the Asphalt 2 section (see the dashed line in the figure). There is a difference of approximately $2 \mathrm{~mm}$ in carbonation depth between the Asphalt section and the Unpaved section. However the difference is not significant when considering the entire difference of carbonation depth. In other words, there is no clear trend.

\subsection{Carbonation depth at different points on beams}

a) Longitudinal beams

Figure 14 shows the distribution along the track direction of average carbonation depths of the different surfaces and different locations of longitudinal beams, measured according to patterns D and E. Figure 15(a) shows the number of longitudinal beams. Figure 15(b) shows the measuring surfaces in Fig. 14. Figure 14 shows no large difference in the carbonation depth at 
different beam positions or surface orientations.

Table 7 shows a summary of measurements for longitudinal beams. The average carbonation depth for all surfaces is approximately $21 \mathrm{~mm}$, which is larger than the value for column surfaces exposed to rainwater. The standard deviation is 2.2 to $5.0 \mathrm{~mm}$ and the coefficient of variation is 0.10 to 0.24 . Since longitudinal beams are not exposed to rainwater, environmental conditions are equal at different points. Additionally, the quality of longitudinal beams does not change in the vertical direction. As a result of these factors, the carbonation depth fluctuates little between different points.

Figure 16 shows the distribution along the track direction of carbonation depths on a surface of R6 and R7 east longitudinal beam measured using pattern D. The carbonation depth fluctuates considerably in the track direction, seemingly due to variations in concrete quality caused by the order of concrete casting. Usually concrete of the longitudinal beam is cast in the axial direction of the beam. Therefore, the concrete quality is thought to fluctuate.

\section{b) Cross beams}

Figure 17 shows the distribution in the track direction of average carbonation depths of the different surfaces of cross beams, measured according to patterns $F$ and $G$. The dotted lines in the figure represent the axis lines of the beams. Figure 18 shows the number of cross beams. The carbonation depths on the north and south surfaces are almost identical, except for those on the $\mathrm{R} 7$ viaduct 7-4 beam. The reason why the values on the 7-4 beam are small is not clear.

Table 8 shows a summary of the measured values for cross beams. The average carbonation depths are approximately 19.7 and $21.4 \mathrm{~mm}$ and the standard deviation is $4.5 \mathrm{~mm}$ (giving coefficients of variation of 0.23 and 0.21 ), which are values equivalent to those of the longitudinal beams. The coefficients of variation of cross beams listed in Table 8 are smaller than the coefficients of variation of columns listed in Table 4. It can be considered, therefore, that the difference in carbonation depth of cross beams is comparatively smaller than the difference in carbonation depth of columns.

Figure 19 shows the distribution of carbonation depths on a surface measured according to pattern $\mathrm{F}$, and demonstrates no obvious pattern of fluctuation of the

Table 7 Summary of measurements for longitudinal beams $(\mathrm{mm})$.

\begin{tabular}{|l|c|c|c|c|c|}
\hline & Max & Min & Ave & $\sigma$ & $\mathrm{Cv}$ \\
\hline East beam (Inner) & 38.0 & 11.1 & 21.2 & 5.0 & 0.24 \\
\hline East beam (Outer) & 26.9 & 14.3 & 21.1 & 3.7 & 0.18 \\
\hline West beam (Inner) & 26.5 & 18.2 & 21.9 & 2.2 & 0.10 \\
\hline
\end{tabular}

carbonation depth. Since the cross beam span of this viaduct is only $2.5 \mathrm{~m}$, the order of concrete casting has less influence on the quality of the concrete, unlike the case of longitudinal beams.

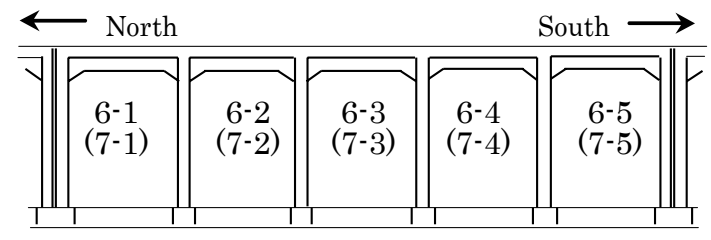

(a) Number of longitudinal beams in R6(R7) viaduct

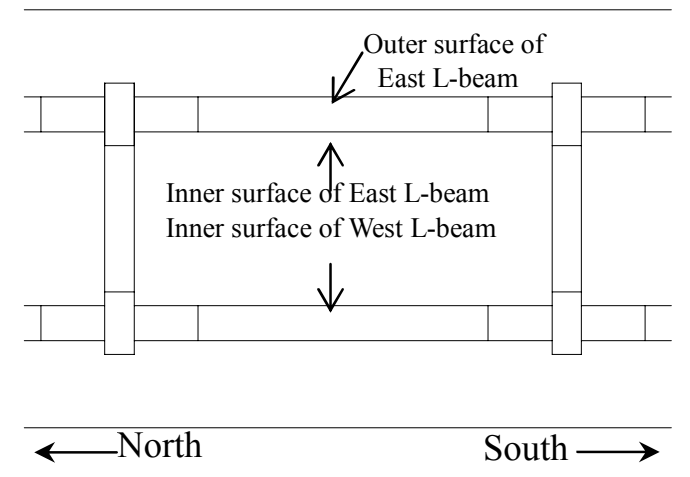

(b) Measuring surfaces

Fig. 15 Measuring points in longitudinal beams.

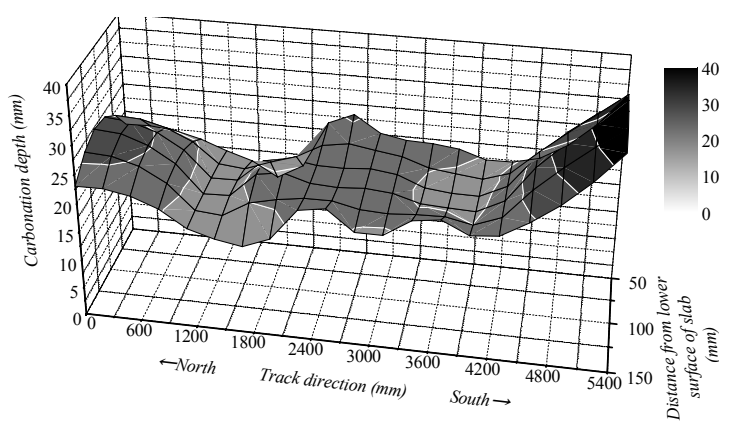

(a) R7 East longitudinal beam (inner surface)

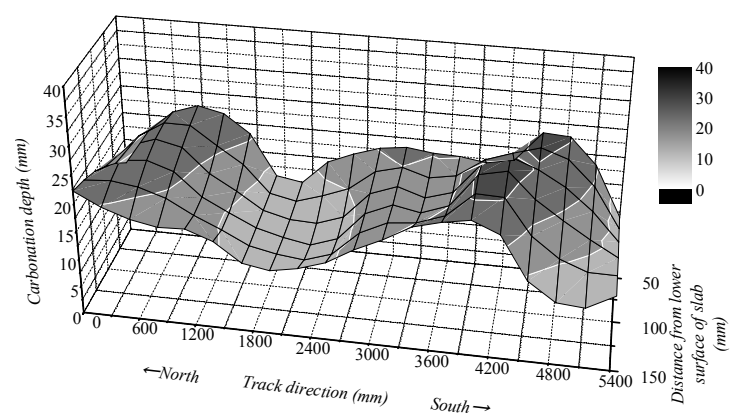

(b) R6 East longitudinal beam (inner surface)

Fig. 16 Distribution of carbonation depth of stringer. 


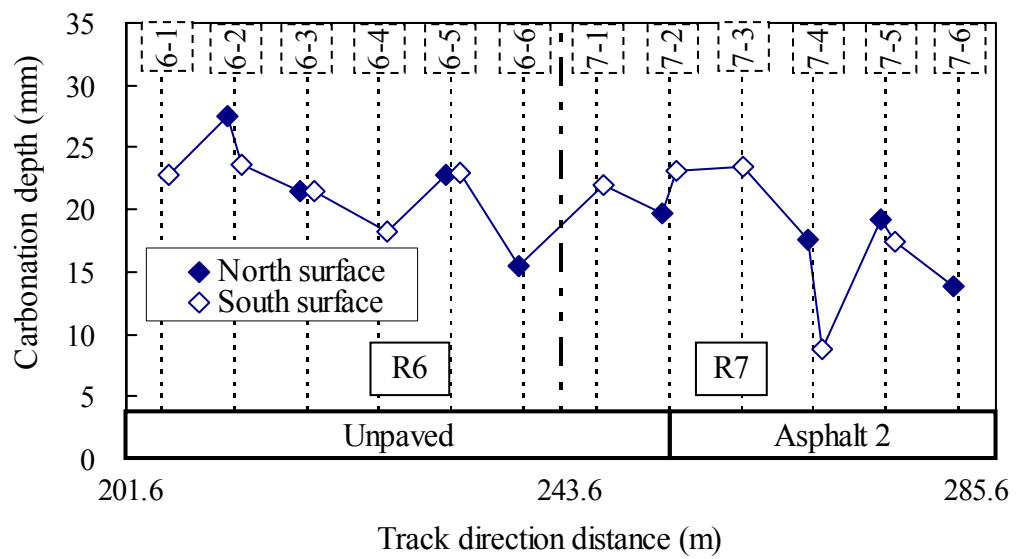

Fig. 17 Distribution of averaged carbonation depth in different cross beam sides.

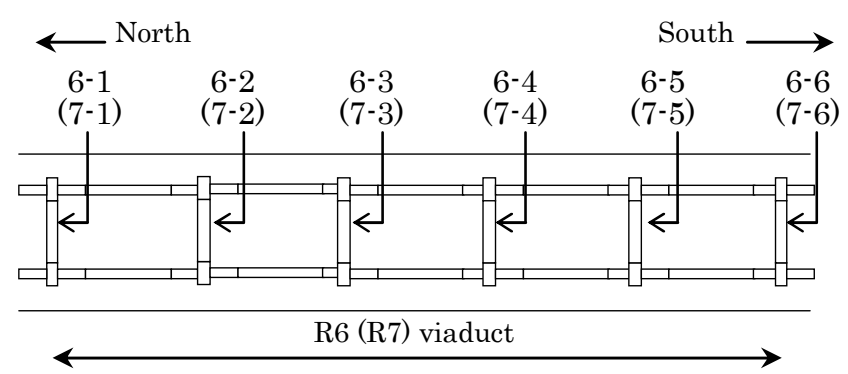

Fig. 18 Number of cross beams.

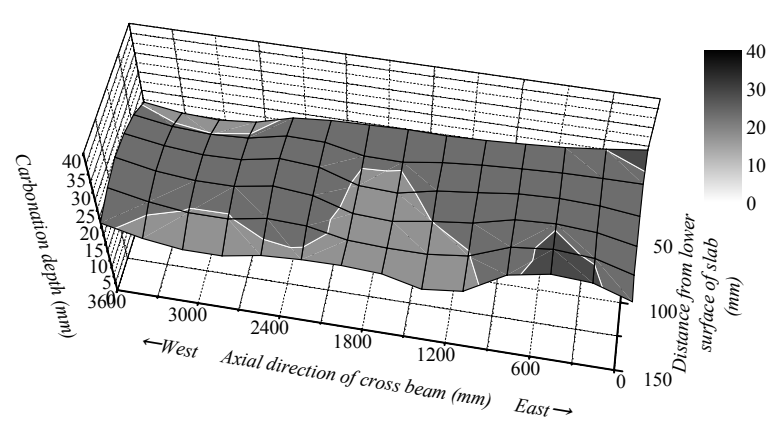

(a) R6 cross beam 6-3 (south surface)

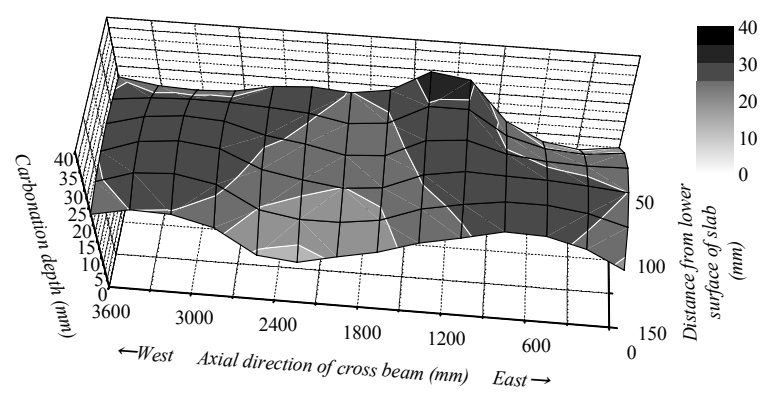

(b) R7 cross beam 7-2 (south surface)

Fig. 19 Distribution of carbonation depth of cross beam.
Table 8 Measurement results for cross beams $(\mathrm{mm})$.

\begin{tabular}{|l|c|c|c|c|c|}
\hline & Max & Min & Ave & $\sigma$ & $\mathrm{Cv}$ \\
\hline North surface & 30.6 & 11.0 & 19.7 & 4.5 & 0.23 \\
\hline South surface & 31.6 & 8.0 & 21.4 & 4.5 & 0.21 \\
\hline
\end{tabular}

\subsection{Carbonation depth at different slab points}

a) Middle slabs

Figure 20 shows the distribution along the track direction of carbonation depths of the middle slab's bottom surface, measured according to patterns $\mathrm{H}$ and $\mathrm{I}$.

The depth shown here is the average for each surface, and the horizontally dotted lines indicate the average for each viaduct.

Table 6 shows average values of carbonation depth of 14.3 to $17.2 \mathrm{~mm}$, which are larger than those found in the columns exposed to rainwater and smaller than those found in beams. Figure 20 shows that the average carbonation depth values are almost constant for all viaducts, except on viaduct $\mathrm{R} 5$ where it is larger. There is no correlation with the ground pavement conditions.

From the above, it can be concluded that carbonation progresses comparatively quickly on the middle slab since it is kept dry and not exposed to rainwater (similar to beams). Since the slab's bottom surface is constantly 


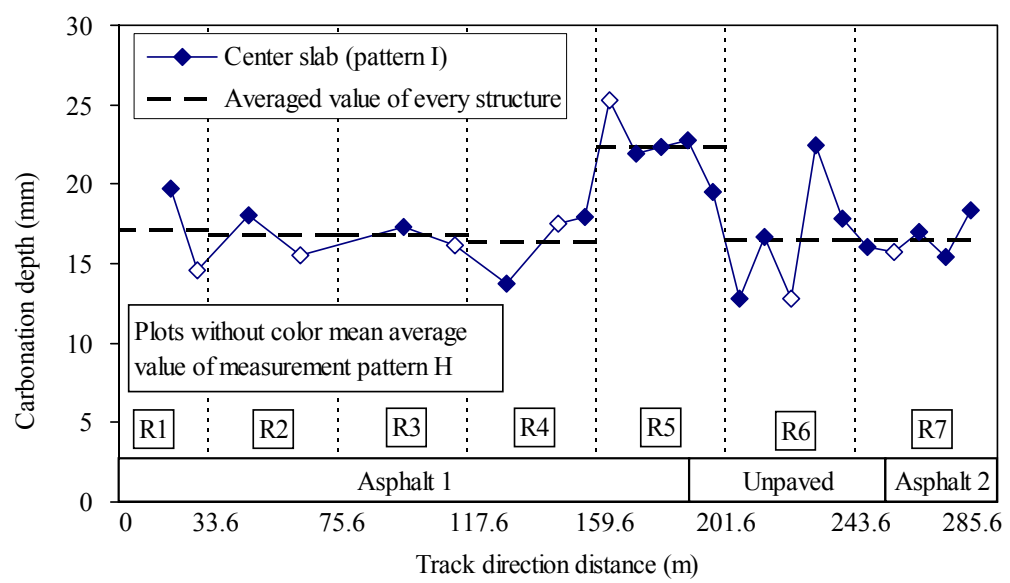

Fig. 20 Distribution of average carbonation depth for middle slab's bottom surface.

protected from the environment and is not affected by ground pavement conditions, the larger carbonation depth on viaduct $\mathrm{R} 5$ seems to be due to a difference in the quality of the concrete used.

Figure 21 shows the distribution of carbonation depths and typical histograms on the slab surfaces of different viaducts. The histograms show the maximum (Max), minimum (Min), average (Ave) and standard deviation $(\sigma)$ of carbonation depth. According to Fig. 21, values of standard deviation are 3.3 to $4.5 \mathrm{~mm}$. Therefore the carbonation depth disperses almost to the same extent at different points, and shows almost no difference of dispersions of carbonation depth between different points. The distribution of carbonation depth shows considerable fluctuation in the track direction, presumably due to variations in concrete quality caused by the order of concrete casting as well as longitudinal beams.

\section{b) Overhanging slab}

Figure 22 shows the distribution along the track direction of carbonation depths in the overhanging slab's bottom surface, measured according to patterns $\mathrm{H}$ and $\mathrm{I}$. The carbonation depth shown here is the average of each slab surface, and the horizontally dotted lines indicate the average for each viaduct.

Table 6 lists average values of carbonation depth of 16.1 to $21.4 \mathrm{~mm}$, which are almost the same as those of the middle slab. Fig 22 shows that the carbonation depth is almost constant across different viaducts, except on viaduct R5 where it is larger. This is the same trend as that observed for the middle slab. It can therefore be considered that the overhanging slab is subject to the same environmental conditions as the middle slab.

Figure 23 shows a sketch of the cross section of the overhanging slab. The carbonation depth was measured at points 1 to 5 in the figure at intervals of $600 \mathrm{~mm}$ along the track direction. Figure $\mathbf{2 4}$ shows the distribution along the track direction of carbonation depths on the overhanging slab bottom of viaduct R6. Numbers 1 to 5 in the figure correspond to the measuring points shown in Fig. 23. Figure 24 shows that the carbonation depths inside the throating are large and fluctuate significantly along the track direction, while at the outside they are approximately $10 \mathrm{~mm}$ smaller than those of the inside and fluctuate gently. This is presumably because the part outside the throating is mostly exposed to rainwater and kept wet.

Figure 25 shows the distribution of carbonation depths on overhanging slab surfaces and typical histograms. The histograms show that the dispersion of carbonation depths is almost the same across different viaducts, except for viaduct R6 where it differs to a relatively large extent. According to Fig. 25, values of standard deviation are 2.6 to $4.3 \mathrm{~mm}$. Therefore, carbonation depth can be considered to disperse to the same extent at different points of the overhanging slab as well as the middle slabs. The distribution of carbonation depths in the track direction does not show a pattern as obvious as in the case of the middle slabs.

The carbonation depth outside the throating is shown in Fig. 25(c). The carbonation depth outside the throating is extremely small when compared to that of the inside.

\section{Application of a durability verification method}

This section discusses the applicability of the design value of carbonation depth $y_{\mathrm{d}}$, calculated by Eq (1) given (JSCE 2002).

$$
y_{d}=\gamma_{c b} \cdot \alpha_{d} \cdot \sqrt{t}
$$

where

$y_{d}: \quad$ Design value of carbonation depth ( $\left.\mathrm{mm}\right)$

$\gamma_{c b}$ : Safety factor in consideration of the dispersion of the design value $y_{d}$ of carbonation depth. (1.0 is used in this discussion).

$\alpha_{\mathrm{d}}$ : Design value of the carbonation rate coefficient $\left(\mathrm{mm} / \sqrt{ }_{\text {years}}\right)$, calculated by Eq (2) (JSCE 2002).

$\alpha_{d}=\alpha_{\mathrm{k}} \cdot \beta_{\mathrm{e}} \cdot \gamma_{\mathrm{c}}$ 

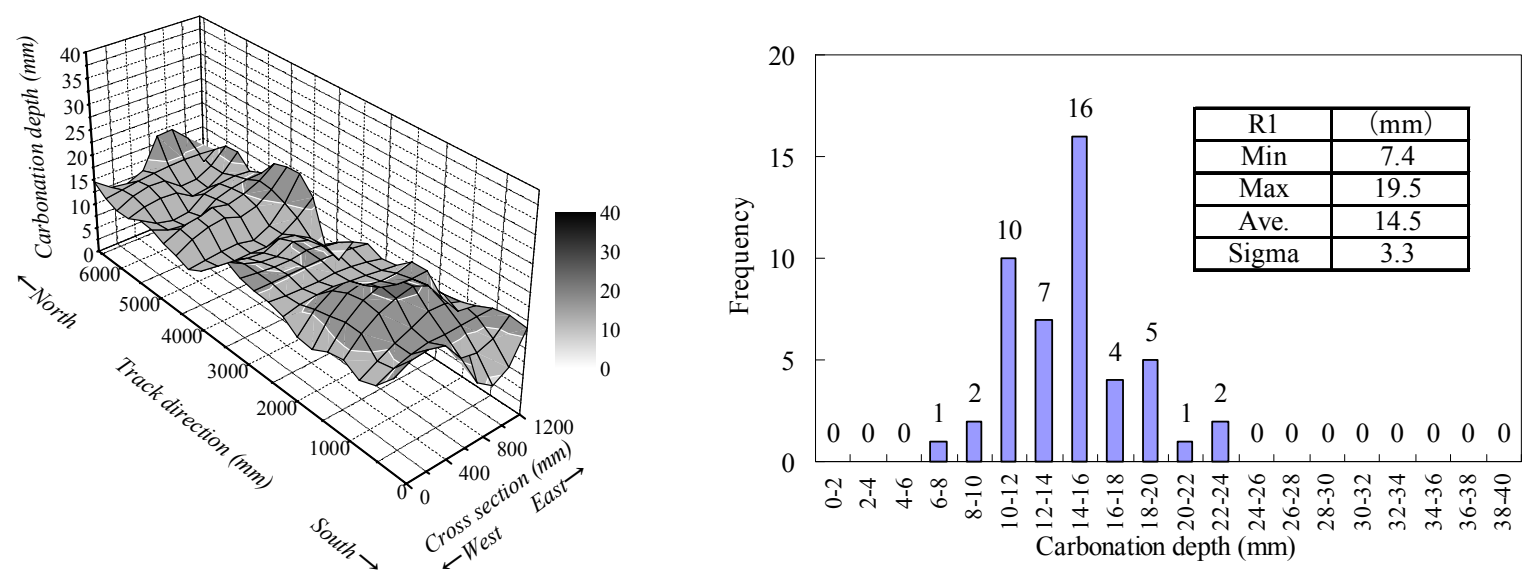

(a) R1 middle slab

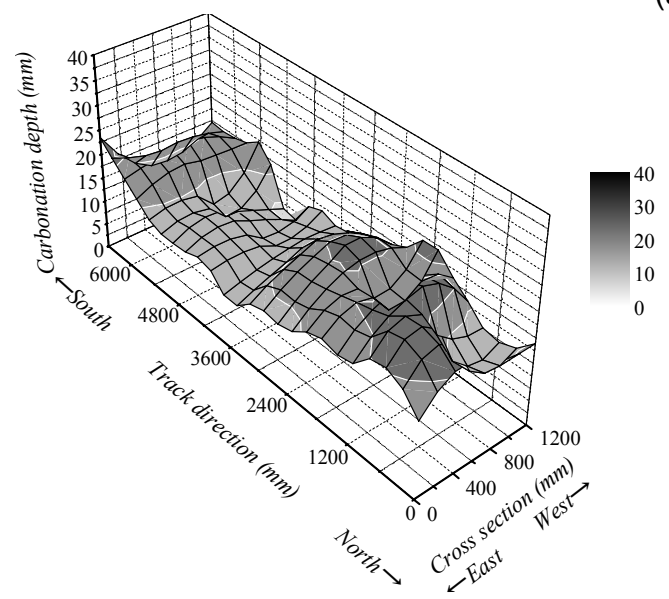

(b) R3 middle slab
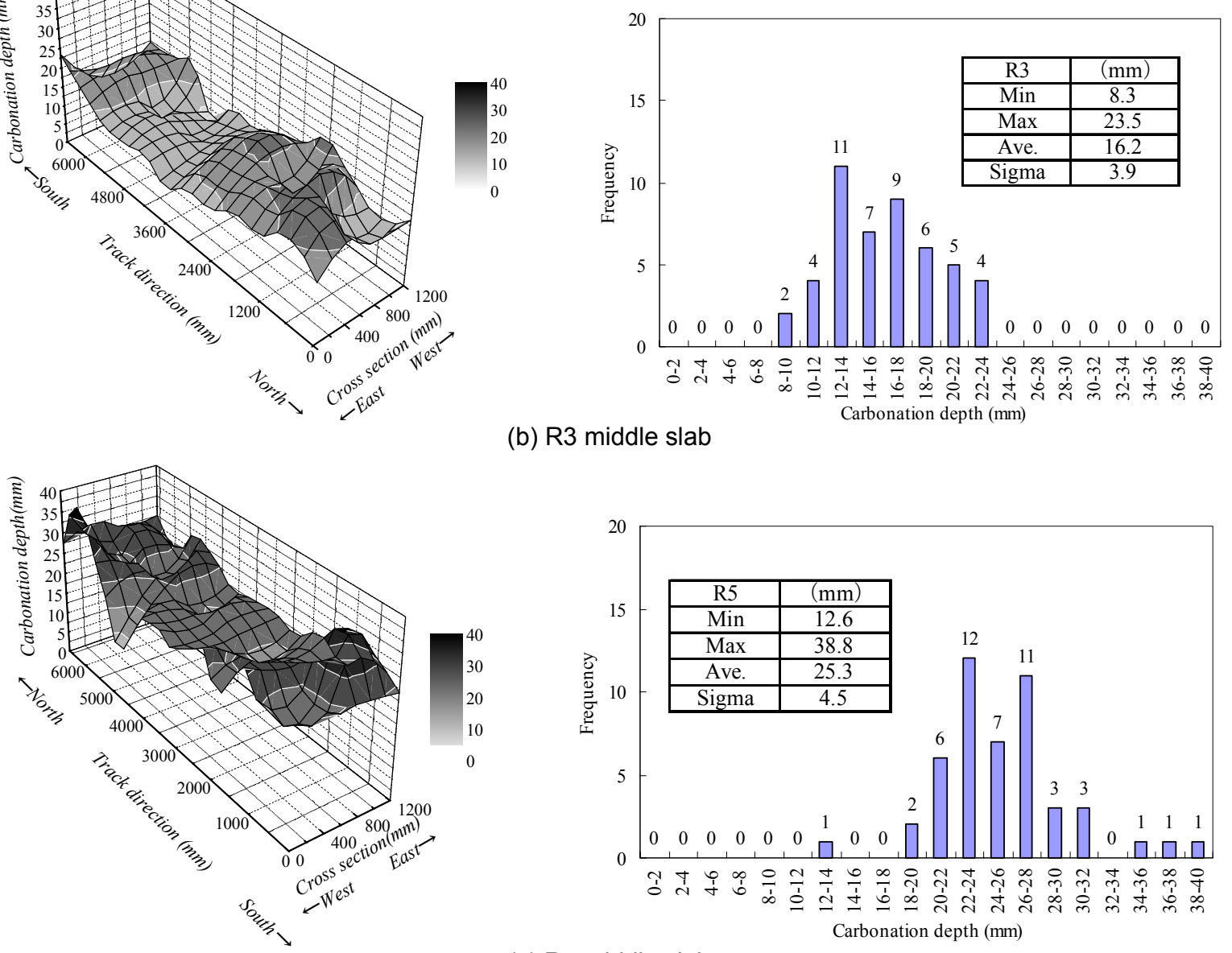

(c) R5 middle slab

Fig. 21 Contours and frequency distribution of carbonation depth in middle slab's bottom surfaces.

$\alpha_{\mathrm{k}}$ : Characteristic value of the coefficient of carbonation depth $(\mathrm{mm} / \sqrt{\text { years }})$, calculated by $\mathrm{Eq}$ (3) (JSCE 2002).

$\alpha_{k}=1.1 \times(-3.57+9.0 \mathrm{~W} / \mathrm{C})$

$W / C$ : Water cement ratio (58\% is used in this discus- sion according to the design specification of this structure).

$\beta_{\mathrm{e}}: \quad$ Factor to evaluate environmental action

$\gamma_{c}: \quad$ Concrete material factor

$t: \quad$ Service period on carbonation (years)

The followings are the values used in this discussion for the coefficient for intensity of environmental action 


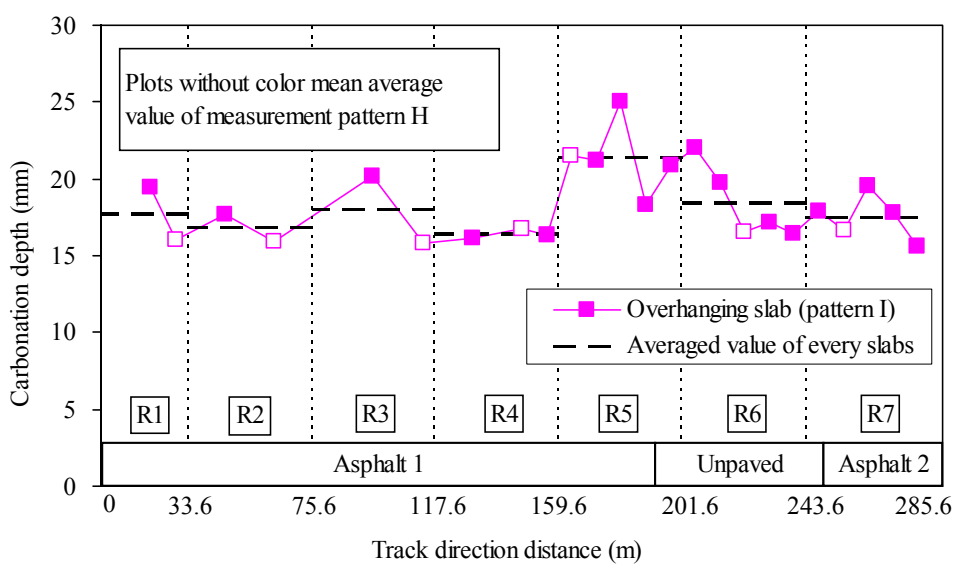

Fig. 22 Distribution of average carbonation depth of overhanging slab's bottom surface.

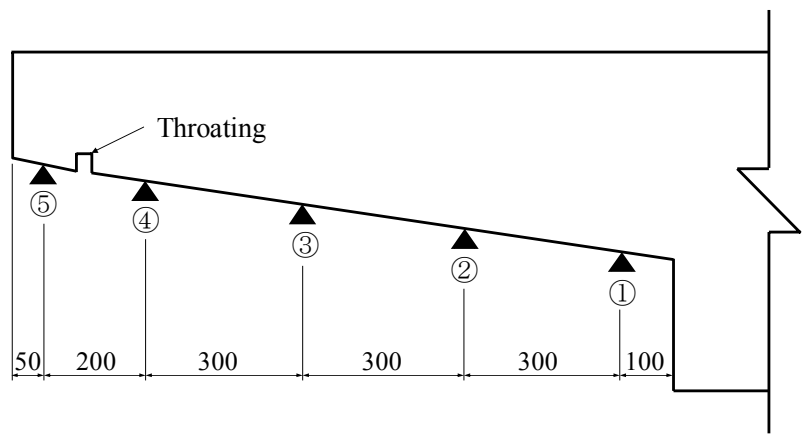

Fig. 23 Outline of throating in overhanging slab and measuring points.

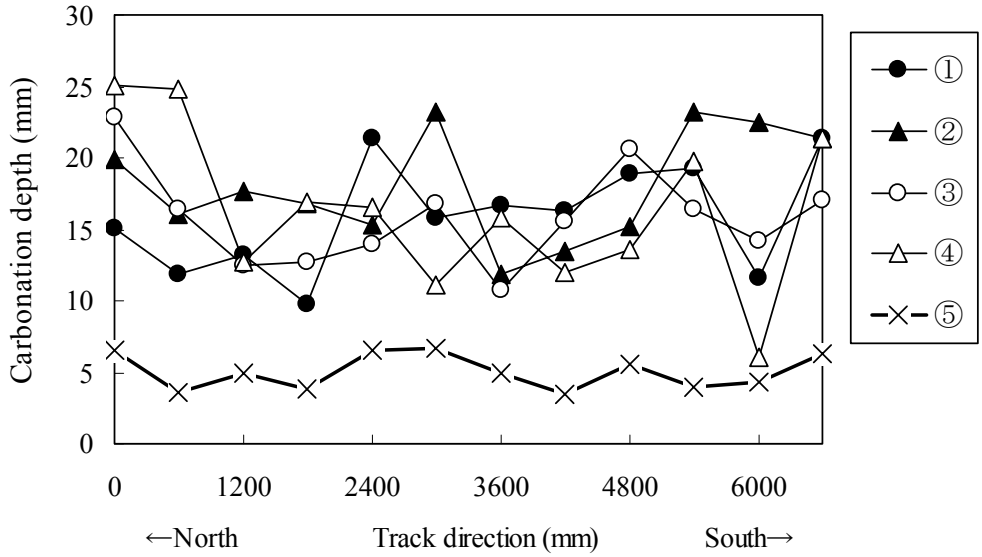

Fig. 24 Distribution of carbonation depth for track direction of R6 overhanging slab's lower surface.

$\beta_{e}$ and concrete material factor $\gamma_{c}$.

* Concrete material factor $\gamma_{c}$

1.3 for points directly below a construction joint of column

1.0 for other points

* Coefficient for intensity of environmental action $\beta \mathrm{e}$

1.6 for column inner surfaces, beam sides and

slab bottoms

1.0 for other points

Figures 26(a) and (b) show the distribution of the differences between the carbonation depths measured in this study and those calculated by using Eq (1). Results in Fig. 26(a) are calculated by using $\beta_{e}=1.0$ and $\gamma_{c}=1.0$. Results in Fig. 26(b) are calculated by using $\beta_{\mathrm{e}}$ and $\gamma_{\mathrm{c}}$ as proposed above. According to Figs. 26(a) and (b), it is confirmed that the calculated values are positioned on the safe side by correcting the coefficients $\beta_{\mathrm{e}}$ and $\gamma_{\mathrm{c}}$ as proposed.

Moreover, approximately $50 \%$ of the difference values, calculated based on the result obtained in this study, fall within $\pm 5 \mathrm{~mm}$, and $80 \%$ within $\pm 10 \mathrm{~mm}$. The quality of the concrete varies from location to location. In other 

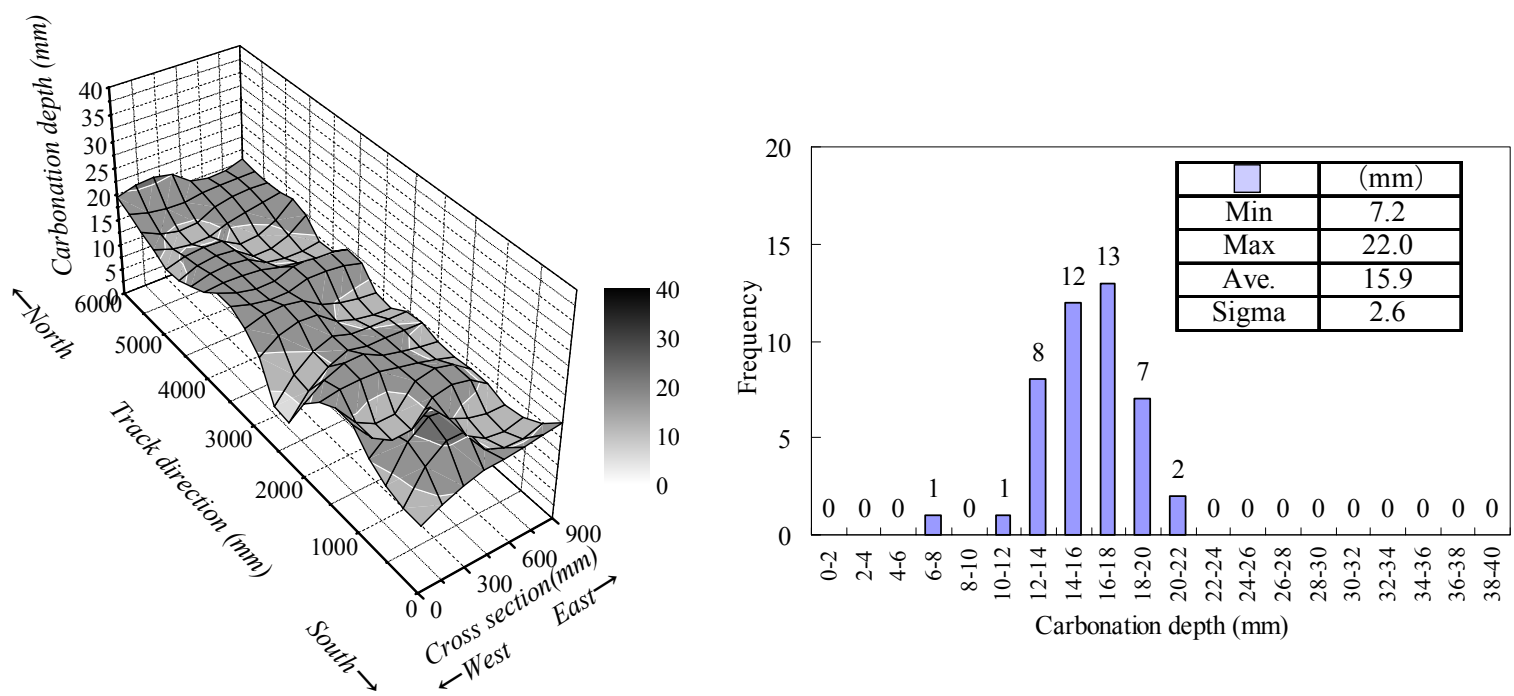

(a) R2 Overhanging slab
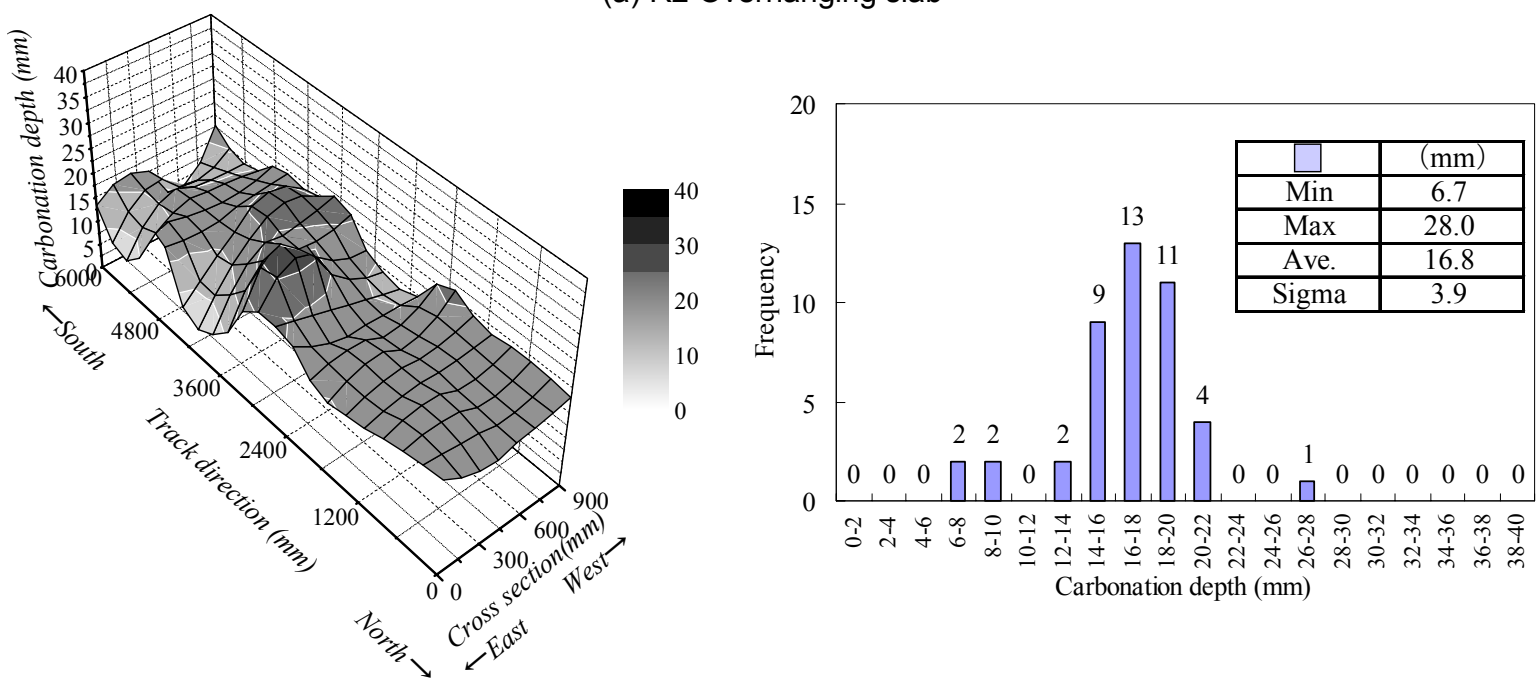

(b) R4 Overhanging slab
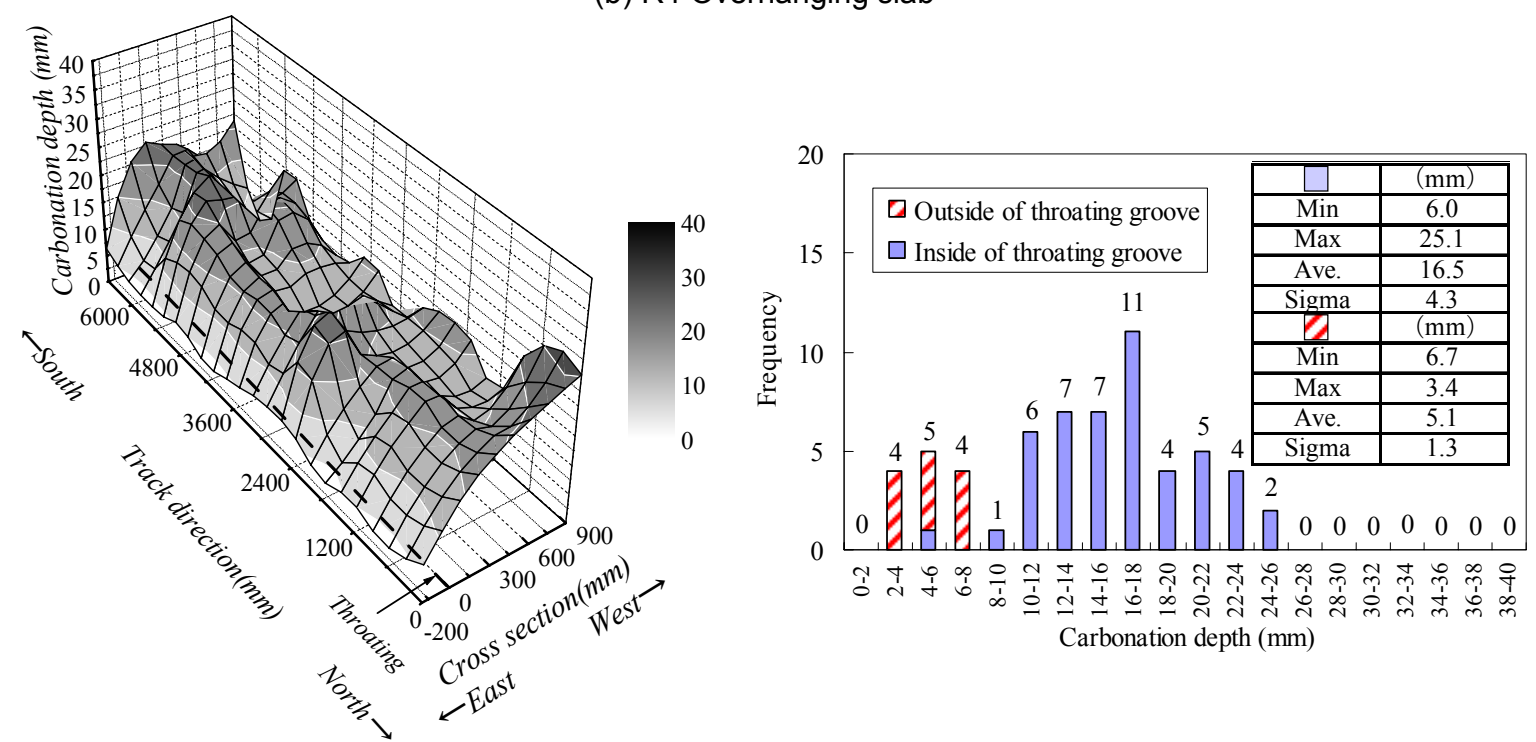

(c) R6 Overhanging slab (including data outside throating)

Fig. 25 Contour and frequency distribution of carbonation depth of the overhanging slab's lower surface. 


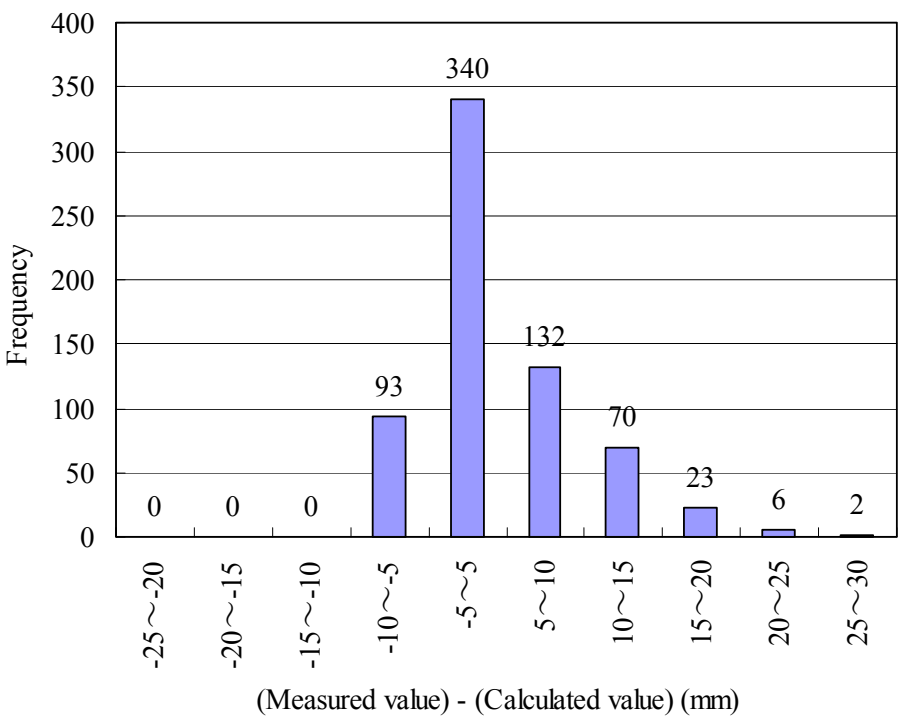

(a) $\beta_{\mathrm{e}}=1.0, \quad \gamma_{\mathrm{c}}=1.0$

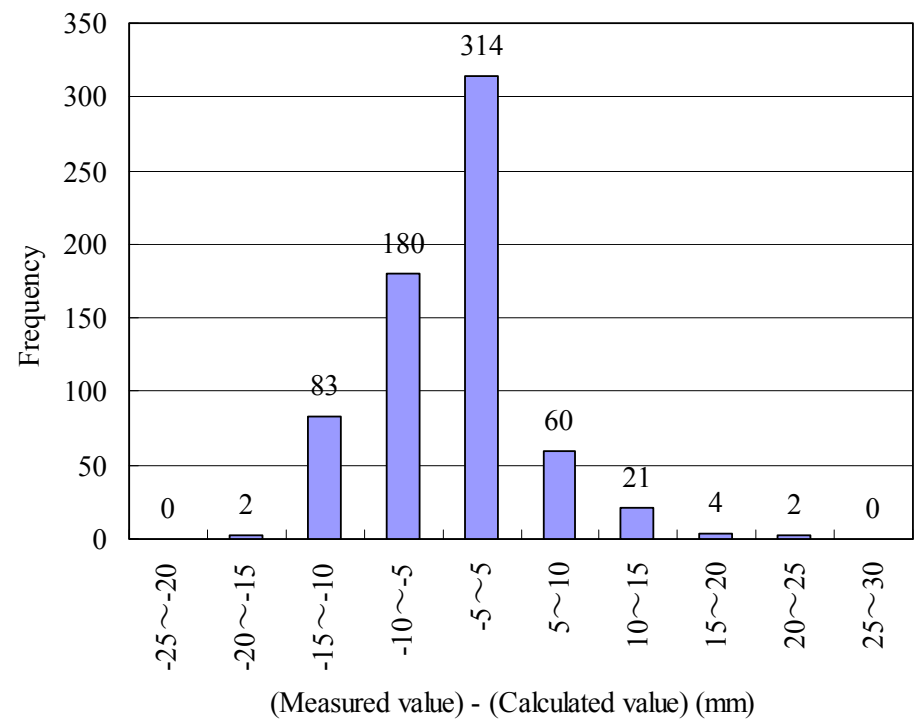

(b) Proposed $\beta_{\mathrm{e}}$ and $\gamma_{\mathrm{c}}$

Fig. 26 Distribution of differences between measured values and calculated values of carbonation depth.

words, the substantial value of $W / C$ becomes small according to the location. In Fig. 26(a) and (b), all calculated values are calculated for $W / C=58 \%$. Therefore, it is thought that that is a reason there are differences in calculated values and measured values.

It is thought that the $\gamma_{\mathrm{c}}$ proposed in this paper can be used when the value of $W / C$ is the same level as $58 \%$.

\section{Conclusions}

In this study, the carbonation depths of a railway $\mathrm{RC}$ rigid-frame viaduct in service since its construction several decades before were measured. Factors affecting carbonation depth at different portions in different members were discussed and the following conclusions were obtained.

(1) The carbonation depth of columns tends to be large at the top of casting lift because bleeding degrades the quality of concrete. It also tends to decrease towards the bottom of columns due to the compacting action of the cast concrete's self-weight.

(2) There are hardly any differences in carbonation depth between columns with different orientations in this survey, since the rigid-frame viaduct structure is composed of slender columns (unlike other structures that consist of large walls) and both north and south surfaces are in the shade of the slabs, hence, environmental conditions do not vary greatly according to the orientation of the surface.

(3) The carbonation depth of column inner surfaces 
and beam/slab bottoms that have no significant exposure to rainwater is large. It can be considered, therefore, that the dry/wet conditions at different portions govern the carbonation depth as an environmental action.

(4) The carbonation depth does not fluctuate greatly at different portions on beams and slabs compared with columns because the dry/wet conditions do not fluctuate greatly at these portions.

(5) The design equation of carbonation depth based on JSCE's standard specifications for concrete structures was modified and it was verified that carbonation depth can be estimated to within a $10 \mathrm{~mm}$ margin of error.

\section{References}

Edamoto, H., Nakazawa, T., Imai, F. and Aranishi, F. (1998). "Progression of carbonation and chloride infiltration of existing reinforced concrete bridges." Proceedings of JCI , 20(2), 985-990. (in Japanese)

Ikeda, M., Shuu, H., Izumi, I., Asai, T., Oshida, F. and Kawabata, S. (1983). "Carbonation of concrete and reinforcement corrosion of existing reinforced concrete structure, Vol. 2, Various factors affect carbonation of concrete and its effect." Summaries of Technical Papers of Annual Meeting of AIJ, 203-204. (in Japanese)

Imai, F. Nakazawa, T. Akagi, M. and Edamoto, H. (1993). "Material deterioration by a difference of region of reinforce concrete bridges." Proceedings of JCI, 15(1), 841-846. (in Japanese)

Ishibashi, T. Kitago, M. (1987). "Effects of various methods of maintenance and repairing applied for lower surface of the concrete slab." Proceedings of JCI, 9(1), 429-434. (in Japanese)

Izumi, T. Kita, T. and Maeda, T. (1986). "Carbonation." Series of durability of concrete structures. Giho-do (in Japanese)

John, J., Hirai, K. and Mihashi, H. (1990). "Influence of environmental moisture and temperature on carbonation of concrete." Concrete Research and Technology, 1(1), 85-94. (in Japanese)

JSCE (1988). "Long-term study on the carbonation of concrete with Fly-ash and corrosion of reinforcement. (final report)", Concrete library, 64. (in Japanese)

JSCE (2002). "Standard specifications for concrete structures-2002, Material and Construction."

Kasai, Y. and Yuasa, N. (1998). "Carbonation of concrete and simple testing method." Nondestructive test, 47(9), 643-648. (in Japanese)

Nihei, T., Sogabe, M., Tanimura, Y. and Higashigawa, K. (2004). "Application of the measurement of carbonation depth by drilling method for the real structure." Proceedings of JCI, 26(1), 2025-2030. (in Japanese)

Saeki, T., Ooga, H. and Nagataki, S. (1989). "Carbonation mechanism of concrete." Proceedings of JCI, 11(1), 563-568. (in Japanese)

Saeki, T., Ooga, H. and Nagataki, S. (1991). "Mechanism of carbonation and prediction of carbonation process of concrete." Concrete Library of JSCE, 23-36.

Saeki, T., Nagataki, S. Ooga, H. and Takami, H. (1991). "Carbonation of moisture supplied concrete by rain." Proceedings of JCI, 13(1), 609-614. (in Japanese)

Shirakawa, T., Shimazoe, Y. and Asou, M. (1996). “A relation between carbonation of concrete and humidity." Proceedings of JCI, 18(1), 723-728. (in Japanese)

Tanimura, Y., Hasegawa, M., Sogabe, M. and Sato, T. (2004)."Durability evaluation method of carbonation for railway RC rigid frame viaducts." Journal of Materials, Concrete Structure and Pavement, 760/V-63, 147-157. (in Japanese)

Uomoto, T. and Takada, Y. (1993). "Factors affecting concrete carbonation ratio." Concrete Library of JACE, 31-44.

Yachida, M. Ishibashi, T. and Satou, T. (1987). "An investigation and study on cracking and corrosion of reinforced concrete bridges." Concrete Library of JSCE, 95-112. 